\title{
Structural basis for recognition of intron branchpoint RNA by yeast MsI5 and selective effects of interfacial mutations on splicing of yeast pre-mRNAs
}

\author{
AGATA JACEWICZ, ${ }^{1}$ LIDIA CHICO, ${ }^{1,2}$ PAUL SMITH, ${ }^{3}$ BEATE SCHWER, $^{2}$ and STEWART SHUMAN ${ }^{1}$ \\ ${ }^{1}$ Molecular Biology Program, Sloan-Kettering Institute, New York, New York 10065, USA \\ ${ }^{2}$ Department of Microbiology and Immunology, Weill Cornell Medical College, New York, New York 10065, USA \\ ${ }^{3}$ Department of Chemistry, Fordham University, Bronx, New York 10458, USA
}

\begin{abstract}
Saccharomyces cerevisiae Msl5 orchestrates spliceosome assembly by binding the intron branchpoint sequence $5^{\prime}$-UACUAAC and, with its heterodimer partner protein Mud2, establishing cross intron-bridging interactions with the U1 snRNP at the $5^{\prime}$ splice site. Here we define the central Msl5 KH-QUA2 domain as sufficient for branchpoint RNA recognition. The 1.8 crystal structure of MsI5-(KH-QUA2) bound to the branchpoint highlights an extensive network of direct and water-mediated protein-RNA and intra-RNA atomic contacts at the interface that illuminate how MsI5 recognizes each nucleobase of the UACUAAC element. The Msl5 structure rationalizes a large body of mutational data and inspires new functional studies herein, which reveal how perturbations of the MsI5·RNA interface impede the splicing of specific yeast pre-mRNAs. We also identify interfacial mutations in MsI5 that bypass the essentiality of Sub2, a DExD-box ATPase implicated in displacing MsI5 from the branchpoint in exchange for the U2 snRNP. These studies establish an atomic resolution framework for understanding splice site selection and early spliceosome dynamics.
\end{abstract}

Keywords: spliceosome assembly; branchpoint binding protein; KH-QUA2 domain

\section{INTRODUCTION}

Yeast pre-mRNA splicing initiates via formation of a complex comprising the U1 snRNP bound at the intron $5^{\prime}$ splice site sequence $5^{\prime}$-GUAUGU and the Msl5-Mud2 protein heterodimer engaged at the intron branchpoint sequence $5^{\prime}$ UACUAAC (for review, see Rymond 2010). The U1 snRNP consists of a trimethylguanosine-capped 568-nt U1 snRNA, a seven-subunit Sm protein ring, and $10 \mathrm{U1}$-specific protein subunits: Prp39, Prp40, Snu71, Snu56, Snp1, Mud1, Luc7, Prp42, Nam8, and Yhc1 (Gottschalk et al. 1998; Schwer et al. 2011). Base-pairing between a hexanucleotide motif in the U1 RNA $5^{\prime}$ leader sequence $\mathrm{m}^{2,2,7}$ GpppAUACUU ACC and the consensus $5^{\prime}$ splice site nucleates an early assembly complex in which U1 snRNP is located at the exon-intron junction (Fig. 1A). Initial recognition of the branchpoint sequence is accomplished by the Msl5 component of an Msl5.Mud2 heterodimer (Berglund et al. 1997; Rain et al. 1998; Wang et al. 2008; Chang et al. 2012). Bridging interactions between U1 snRNP at the $5^{\prime}$ splice site and Msl5.Mud2 at the branchpoint stabilize a commit-

Corresponding authors: bschwer@med.cornell.edu; s-shuman@ski. mskcc.org

Article published online ahead of print. Article and publication date are at http://www.rnajournal.org/cgi/doi/10.1261/rna.048942.114. ment complex (Abovich and Rosbash 1997; Rutz and Séraphin 1999) and prepare a scaffold for subsequent recruitment of the U2 snRNP to the branchpoint. Base-pairing interactions between a segment of the U2 snRNA and the intron branchpoint UACUAAC motif, to form a short duplex with an extrahelical adenosine (Fig. 1A), are essential to generate a catalytically active spliceosome. Establishing these RNA.RNA contacts mandates ejection of Msl5 from its position directly over the branchpoint, allowing its replacement by U2. This process is thought to be triggered by the DExD-box helicase Sub2, acting to disrupt or remodel bridging contacts mediated by Mud2 (Kistler and Guthrie 2001; Libri et al. 2001; Zhang and Green 2001; Wang et al. 2008).

The Msl5 protein that contacts the branchpoint is essential for yeast viability (Abovich and Rosbash 1997). The 476amino acid Msl5 polypeptide consists of a central domain implicated in RNA binding, flanked by an $\mathrm{N}$-terminal domain that binds Mud2, and a C-terminal proline-rich domain (Fig. 2A). Neither Mud2, nor the N-terminal

(C) 2015 Jacewicz et al. This article is distributed exclusively by the RNA Society for the first 12 months after the full-issue publication date (see http://rnajournal.cshlp.org/site/misc/terms.xhtml). After 12 months, it is available under a Creative Commons License (Attribution-NonCommercial 4.0 International), as described at http://creativecommons.org/licenses/by$\mathrm{nc} / 4.0 \%$. 
A
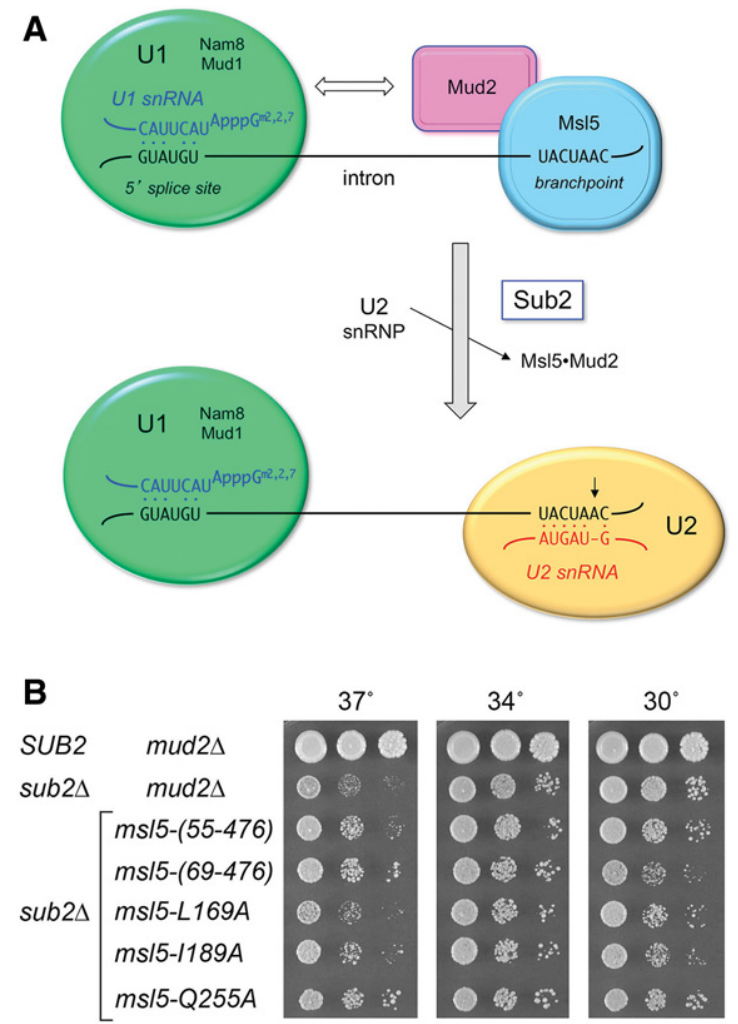

FIGURE 1. Yeast Ms15 and Sub2 in early spliceosome assembly. (A) Bridging interactions between U1 snRNP at the 5'SS and Msl5.Mud2 at the branchpoint prepare a scaffold for subsequent recruitment of the U2 snRNP to the branchpoint. Exchange of U2 snRNP for Msl5.Mud2 is mediated by the DExD-box ATPase Sub2. (B) Mutations of Msl5 RNA-binding residues bypass the essentiality of Sub2. Yeast SUB2 mud $2 \Delta$ and sub2 $\Delta$ mud $2 \Delta$ cells and sub2 2 msl5 $\Delta$ cells harboring the indicated MSL5 allele on a CEN HIS3 plasmid were grown in liquid cultures to mid-log phase. The cultures were adjusted to $A_{600}$ of 0.1 and aliquots of serial dilutions were spotted to YPD agar and incubated at $37^{\circ} \mathrm{C}, 34^{\circ} \mathrm{C}$, or $30^{\circ} \mathrm{C}$ as indicated.

segment of Msl5 that binds Mud2, nor the C-terminal proline-rich domain of Msl5 is important for yeast vegetative growth (Abovich et al. 1994; Chang et al. 2010, 2012). In contrast, the Msl5 central domain is essential, presumably reflective of its interactions with the intron branchpoint. In previous studies (Chang et al. 2012; Schwer et al. 2013), we conducted extensive alanine scanning mutagenesis of the central KH-QUA2 module of Msl5, targeting amino acids implicated in RNA binding via reference to the NMR structure of the homologous human branchpoint binding protein SF1 in complex with a yeast consensus branchpoint RNA (Liu et al. 2001). Alanine mutations of only four Msl5 amino acids were unconditionally or conditionally lethal: Arg172, Arg190, Leu256, and Leu259 (Schwer et al. 2013). In contrast, alanine mutations of nine other Msl5 amino acids that contact the consensus branchpoint elicited no growth phenotypes. However, we found allele-specific synergies of otherwise benign RNA binding site mutations with (i) mutations in the U1 snRNA; (ii) deletion of inessential U1 snRNP subunits Mud1 and Nam8; (iii) deletion of the Msl5 binding partner Mud2; (iv) a Y24A mutation of nuclear cap-binding complex subunit $\mathrm{Cbc} 2$; and (v) deletion of Tgs1, the enzyme responsible for snRNA cap trimethylation (Chang et al. 2012; Qiu et al. 2012; Schwer et al. 2013). These results discriminated essential from optional branchpoint RNA contacts and imply that the effects of hypomorphic Msl5 changes that weaken branchpoint binding are buffered by interactions with the U1 snRNP that are mediated, at least in part, via the Mud2 subunit of the Msl5.Mud2 heterodimer.

Although the genetic data are substantial, their interpretation rests on the assumption that the NMR structure of human SF1 is portable to Msl5's RNA interface. To query this issue, and establish a firmer foundation for dissecting the role of Msl5.branchpoint interactions in yeast pre-mRNA splicing, we herein (i) delineate a minimal branchpoint RNA-binding KH-QUA2 domain of Msl5 (from amino acids 144 to 271); (ii) report the $1.8 \AA$ crystal structure of Msl5-(KH-QUA2) in complex with a consensus yeast branchpoint RNA; (iii) use the crystal structure to guide new mutational analysis of Msl5; and (iv) discover how perturbations of the Msl5.RNA interface affect the splicing of specific yeast mRNAs. In addition, we identify specific RNA interfacial mutations in Msl5 that bypass the requirement for Sub2 for vegetative growth.

\section{RESULTS}

\section{Msl5-(KH-QUA2) is an autonomous branchpoint- specific RNA binding domain}

Prior investigators had analyzed the RNA binding properties of recombinant versions of the central segment of yeast Msl5 spanning amino acids 147-331, which includes a predicted KH-QUA2 domain and two downstream zinc-knuckle modules (Fig. 2A), or a shorter version from amino acids 147 to 296, which lacks the second of the two zinc-knuckles (Berglund et al. 1997; Garrey et al. 2006). It was reported that Msl5-(147-269), which includes only the KH-QUA2 module, was unable to bind to branchpoint RNA (Garrey et al. 2006). Our genetic dissection of Msl5 function in vivo indicated that (i) the truncated allele MSL5-(1-298), lacking the second zinc-knuckle and all distal elements, sufficed for normal vegetative growth; (ii) an MSL5-(1-272) strain, lacking both zinc knuckles, was viable but grew more slowly than MSL5 cells; and (iii) the MSL5-(1-263) truncation, which trims into the QUA2 module, was lethal (Chang et al. 2012). In order to better delineate the margins of an autonomous functional unit for branchpoint RNA recognition, we produced a recombinant protein, Msl5-(144-271), with Nand C-terminal margins analogous to the KH-QUA2 domain of mammalian SF1/BBP (Liu et al. 2001). The purified tagfree Ms15-(KH-QUA2) protein eluted as a monomer during gel filtration (not shown) and migrated as a $14-\mathrm{kDa}$ species during SDS-PAGE (Fig. 2B), consistent with the predicted mass of the recombinant polypeptide. 


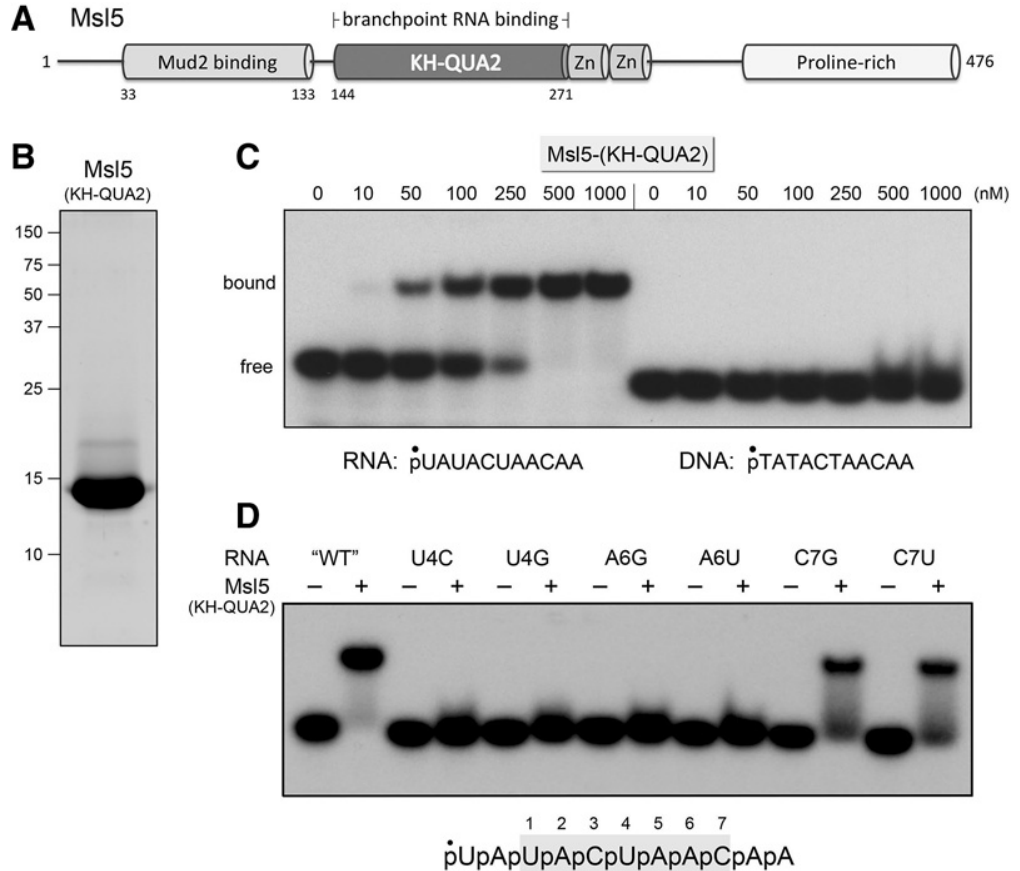

FIGURE 2. Ms15-(KH-QUA2) is an autonomous branchpoint-specific RNA binding domain. (A) Domain organization of yeast Ms15. The 476-amino acid Msl5 polypeptide is depicted as a linear array with the $\mathrm{N}$-terminus at left and the $\mathrm{C}$-terminus at right, and the known or imputed domains drawn as cylinders spanning their segments of the primary structure. $(B)$ An aliquot $(7.5$ $\mu \mathrm{g}$ ) of purified recombinant Msl5-(KH-QUA2) (amino acids 147-271) was analyzed by SDSPAGE. The Coomassie blue-stained gel is shown. The positions and sizes $(\mathrm{kDa})$ of marker polypeptides are indicated at left. $(C)$ Nucleic acid binding reaction mixtures $(10 \mu \mathrm{L})$ containing 25 mM Tris-HCl, pH 7.5, 1 mM DTT, $10 \%$ glycerol, $100 \mathrm{nM} \mathrm{5}^{\prime 32}$ P-labeled 11-mer RNA (left panel) or DNA (right panel) oligonucleotide as specified, and Msl5-(KH-QUA2) as specified were incubated at $4^{\circ} \mathrm{C}$ for $20 \mathrm{~min}$. The mixtures were analyzed by electrophoresis at $4^{\circ} \mathrm{C}$ for $90 \mathrm{~min}$ at $110 \mathrm{~V}$ through a $15-\mathrm{cm}$ native $10 \%$ polyacrylamide gel containing $22.5 \mathrm{mM}$ Tris-borate, $2.5 \%$ glycerol. An autoradiograph of the gel is shown. The species corresponding to free and Msl5(KH-QUA2)bound oligonucleotides are indicated at left. $(D)$ RNA binding reaction mixtures containing 25

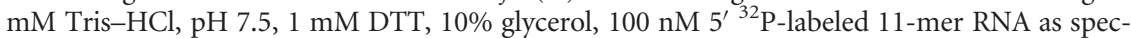
ified, and either no protein (-) or $500 \mathrm{nM}$ Msl5-(KH-QUA2) (+) were incubated at $4^{\circ} \mathrm{C}$ for 20 $\mathrm{min}$. The mixtures were analyzed by native PAGE as in $C$. An autoradiograph of the gel is shown. The wild-type branchpoint-containing RNA is shown at bottom, with the consensus yeast branchpoint sequence shaded gray and the seven branchpoint nucleobases numbered from $5^{\prime}$ to $3^{\prime}$.

RNA binding was gauged by incubating increasing concentrations of Msl5-(KH-QUA2) with $100 \mathrm{nM} \mathrm{5^{ \prime }}{ }^{32} \mathrm{P}$-labeled 11mer RNA containing the consensus branchpoint sequence flanked by $2 \mathrm{nt}$ on either end. Analysis by native PAGE revealed the concentration dependent formation of a discrete protein.RNA complex of retarded mobility (Fig. 2C), with 94\% binding at $1000 \mathrm{nM}$ Msl5-(KH-QUA2). By quantifying the extent of binding as a function of Msl5-(KH-QUA2) concentration using the data from three independent experiments, we determined that half saturation of binding to $100 \mathrm{nM}$ RNA was attained at $140 \mathrm{nM}$ Msl5-(KH-QUA2) (not shown). In contrast, Msl5-(KH-QUA2) failed to bind at all to $100 \mathrm{nM} \mathrm{5}{ }^{\prime}{ }^{32} \mathrm{P}$-labeled 11-mer DNA of identical nucleobase sequence (with $\mathrm{T}$ instead of $\mathrm{U}$ ) at input protein concentration up to $1000 \mathrm{nM}$ (Fig. 2C). We conclude that Msl5-(144-271) comprises an autonomous branchpoint RNA binding domain of Msl5.
We proceeded to briefly interrogate the nucleobase specificity of branchpoint recognition by Msl5-(KH-QUA2), by testing binding to versions of the 11mer RNA ligand with alternative nucleosides within the yeast consensus branchpoint sequence, henceforth numbered as $U^{1} A^{2} C^{3} U^{4} A^{5} A^{6} C^{7}$. We focused on three positions-U4, A6, and C7-making a pyrimidine and a purine substitution at each (Fig. 2D). The U4C, U4G, A6G, and A6U changes abolished RNA binding by $500 \mathrm{nM}$ Msl5-(KH-QUA2), a level of protein that sufficed for efficient complex formation with the consensus "wildtype" branchpoint RNA (Fig. 2D). The stringent requirements of Msl5 for $\mathrm{U}^{4}$ and $\mathrm{A}^{6}$ are consistent with the comprehensive database of spliced yeast RNAs compiled by the Ares laboratory (http ://intron.ucsc.edu/yeast4.1/) in which there are no naturally occurring yeast introns that have a nucleobase other than $\mathrm{U}$ at position 4 and $A$ at position 6 . In contrast, Msl5-(KH-QUA2) did bind to the C7G and C7U variants (Fig. 2D). The presence of a diffuse smear of radiolabeled material between the free RNA and the discrete protein.RNA complexes formed on the variant $\mathrm{C} 7 \mathrm{G}$ and $\mathrm{C} 7 \mathrm{U}$ RNAs (which was not characteristic of the complex formed on the wild-type RNA) suggested that the C7G and C7U complexes were prone to dissociate during the electrophoresis procedure. The ability of Msl5-(KH-QUA2) to recognize C7U, albeit less stably than the consensus branchpoint, is consistent with the annotation of four spliced yeast RNAs that naturally have $\mathrm{U}$ in lieu of $\mathrm{C}^{7}$ at their intron branchpoints (SCS22, HRB1, YKR005c, $G M C 2$ ). Because there are no yeast introns that have a purine instead of $\mathrm{C}^{7}$, notwithstanding our finding that $\mathrm{C} 7 \mathrm{G}$ is engaged by Msl5-(KH-QUA2) about as well as C7U, we infer that the pyrimidine-only restriction is imposed at a step other than branchpoint recognition by Msl5. The likely restriction point is the formation of the bulged RNA duplex between $\mathrm{U} 2$ snRNA and the branchpoint, in which the branchpoint $\mathrm{C}^{7}$ base pairs with a $G$ base in the U2 snRNA (Fig. 1A).

\section{Crystal structure of Msl5-(144-271) bound to branchpoint RNA}

Having validated the branchpoint RNA binding specificity of the isolated KH-QUA2 domain, we aimed to crystallize the domain in a complex with the consensus branchpoint. 
Native and SeMet-substituted Msl5(KH-QUA2) proteins were preincubated with an equimolar concentration of 11mer branchpoint RNA. Crystals were grown by sitting drop vapor diffusion at room temperature. A native Msl5-(KHQUA2) crystal diffracted X-rays to $1.8 \AA$ resolution. A SeMet-Msl5-(KH-QUA2) crystal diffracted X-rays to $2.18 \AA$ resolution. The SeMet-Msl5-(KH-QUA2) crystals were in space group P422 with one protomer in the asymmetric unit. SAD phasing yielded electron density maps that revealed a bound RNA, the sequence of which was legible as UACUAAC (Supplemental Fig. S1). The SeMet-Msl5(KH-QUA2).RNA structure was refined to $R / R_{\text {free }}$ of $17.2 / 21.5$ at $2.2 \AA$ resolution. The model of the Msl5 protein extended from Thr146 to Arg271. The SeMetMsl5-(KH-QUA2) model was used for molecular replacement to derive the structure of the native protein, which crystallized in space group $\mathrm{P} 2_{1}$ with four Msl5.RNA complexes in the asymmetric unit. The native $1.8 \AA$ structure was refined to $R / R_{\text {free }}$ of $17.5 / 20.6$. The folds of the four Msl5 protomers were virtually identical to one another (pairwise rmsd values of $0.48-1.0 \AA$ ) and each protomer was bound to UACUAAC. The model of the native A protomer extended from Pro145 to Glu268 and superimposed on the SeMet-Msl5 structure with rmsd of 0.71 A. Henceforth we will focus on the A protomer.

The tertiary structure of Msl5-(KHQUA2) is shown in stereo view in Figure 3A. The secondary structure elements are aligned over the Msl5 amino acid sequence in Figure 3C. Msl5-(KHQUA2) comprises a three-strand $\beta$ sheet with topology $\beta 1 \uparrow \cdot \beta 3 \downarrow \cdot \beta 2 \uparrow$. The sheet is flanked on one side by four $\alpha$ helices and on the other by loops and a $3_{10}$ helix (Fig. 3A). The branchpoint RNA binds in a groove between the helices and the $\beta$ sheet, with the $5^{\prime}$ end of the RNA engaged by the C-terminal $\alpha 4$ helix (the QUA2 module) and the $3^{\prime}$ end of the RNA engaged by $\beta$ sheet and the $3_{10}$ helix of the $\mathrm{KH}$ module (Fig. 3A). A surface electrostatic model of Msl5-(KH-QUA2) is shown in stereo view in Figure 3B, which features a continuous tract of positive surface potential surrounding the RNA ligand. The surface model highlights how the sequential RNA
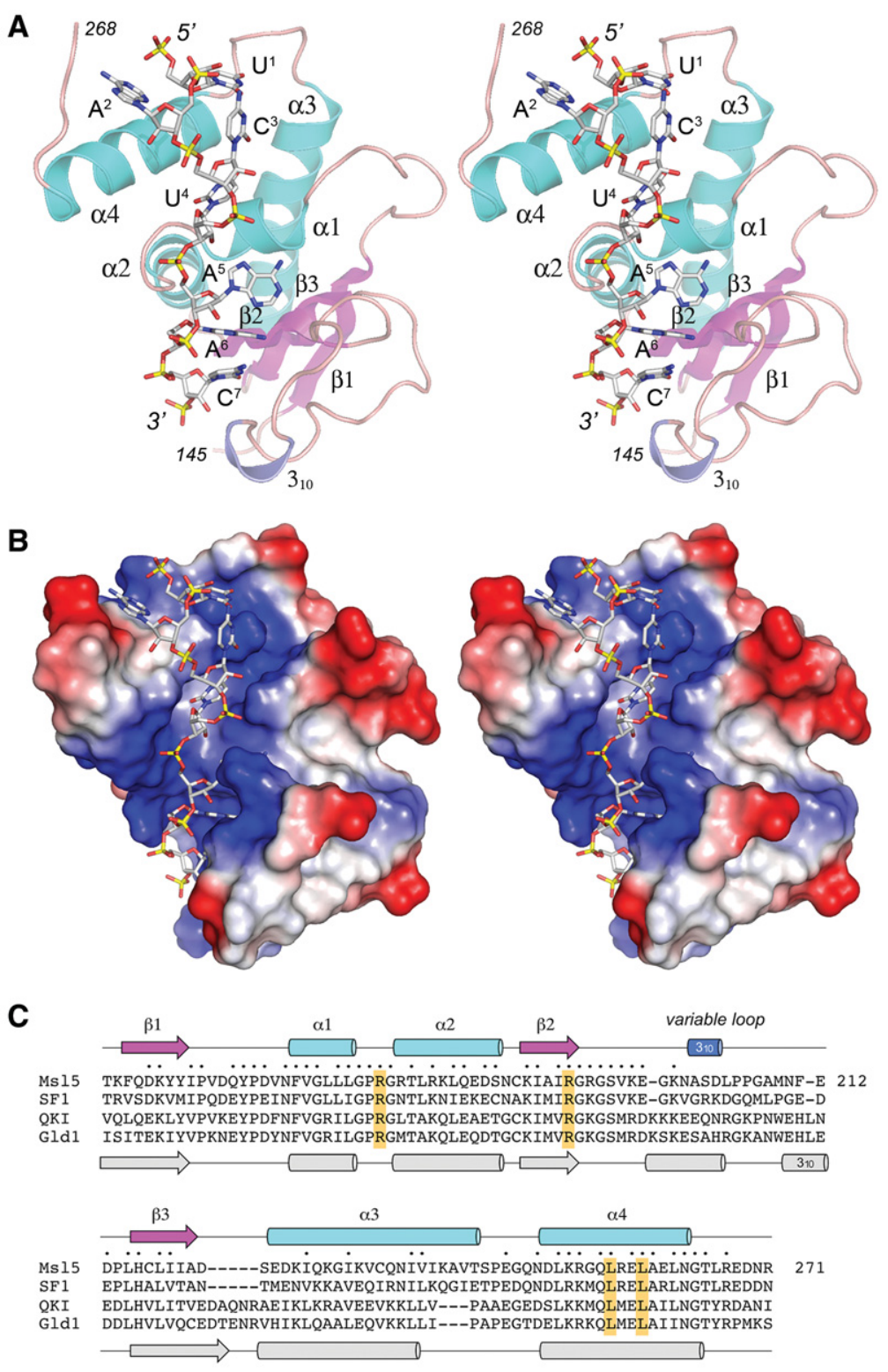

FIGURE 3. Structure of the Msl5-(KH-QUA2) b branchpoint RNA complex. (A) A stereo view of the tertiary structure is shown as a cartoon model, with $\beta$ strands colored magenta, $\alpha$ helices colored cyan, and a $3_{10}$ helix colored blue. The $\mathrm{N}$ and $\mathrm{C}$ termini (amino acids 145 and 268) are indicated. The branchpoint RNA is depicted as a stick model. (B) A stereo view of a surface electrostatic model of Msl5-(KH-QUA2), generated in Pymol, is shown, with the branchpoint RNA depicted as a stick model. (C) The secondary structure elements of yeast Msl5-(KH-QUA2) (colored as in A) are shown above the Msl5 amino acid sequence, with $\beta$ strands rendered as arrows and helices as cylinders. The Msl5 primary structure is aligned to those of the homologous human SF1, human QKI, and C. elegans GLD-1 proteins. Gaps in the alignment are indicated by dashes. Positions of amino acid side chain identity/similarity in all four polypeptides are indicated by dots above the sequence. The secondary structure elements of GLD-1 (colored gray) are shown below its amino acid sequence. The four conserved amino acids that are important per se for Msl5 function in vivo (as determined previously by alanine scanning) are highlighted in yellow boxes.

nucleobases are splayed in different directions from the phosphodiester backbone and how the nucleobases are packed closely against the protein surface (Fig. 3B). With the exception of the A6-C7 step, there is no base stacking in the branchpoint RNA when bound to Msl5 (Fig. 3A). 
A DALI search (Holm et al. 2008) of the Msl5-(KHQUA2) structure against the protein database identified human Quaking (QKI) ( $Z$ score 14.5) and C. elegans GLD-1 ( $Z$ score 13.8 ) as the top hits among $\mathrm{X}$-ray structures (Teplova et al. 2013), followed by the NMR structure of human SF1 ( $Z$ score 10.9) (Supplemental Table S2; Liu et al. 2001). A structure-guided alignment of the amino acid sequences of these four KH-QUA2 proteins highlights 60 positions of side chain identity/similarity in all four (denoted by in Fig. 3C). The aligned tertiary structures of RNA-bound Msl5, QKI, GLD-1 and SF1 are shown in Figure 4. The salient differences between Msl5 and QKI/GLD-1 reside in the "variable loop" between the $\beta 2$ and $\beta 3$ strands. The amino acid sequences of the loop are virtually identical in QKI and GLD-1, but poorly conserved in Msl5 (Fig. 3C). Whereas the Msl5 loop has only a 3-amino acid segment of secondary structure (a $33_{10}$ helix), the QKI/GLD-1 loop comprises a 7amino acid $a$ helix and a 4 -amino acid $33_{10}$ helix (Figs. 3C, 4). In contrast, the loop in the NMR structure of SF1 has no ordered secondary elements (Fig. 4). The structure of the QUA2 component of SF1 differs significantly from that of Msl5, being a continuous a helix in Msl5 versus a hybrid $3_{10}$ - $a$ helix in SF1 (Fig. 4). Also, in the view shown in Figure 4, the QUA2 element is displaced downward in SF1 compared with its position in Msl5 and the two other $\mathrm{KH}$ QUA2 proteins. These structural differences might explain prior findings, based on studies with chimeric yeast-human branchpoint binding proteins, that the QUA2 domain dictates the higher RNA affinity and sequence specificity of yeast Msl5 versus human SF1 (Garrey et al. 2008).

\section{Structural basis for branchpoint RNA recognition by MsI5}

The atomic contacts at the Msl5 branchpoint RNA interface are shown in Figure 5, in overlapping triplets of RNA nucleotides, as $\mathrm{U}^{1} \mathrm{~A}^{2} \mathrm{C}^{3}$ in panel $\mathrm{A}, \mathrm{C}^{3} \mathrm{U}^{4} \mathrm{~A}^{5}$ in panel $\mathrm{B}$, and $\mathrm{A}^{5} \mathrm{~A}^{6} \mathrm{C}^{7}$ in panel $C$. The $\mathrm{A}^{2}$ nucleobase is unique in adopting the $c i s$ conformation of adenine over the ribose; the six other nucleosides are all in anti conformation. The $\mathrm{A}^{6}$ ribose is unique in
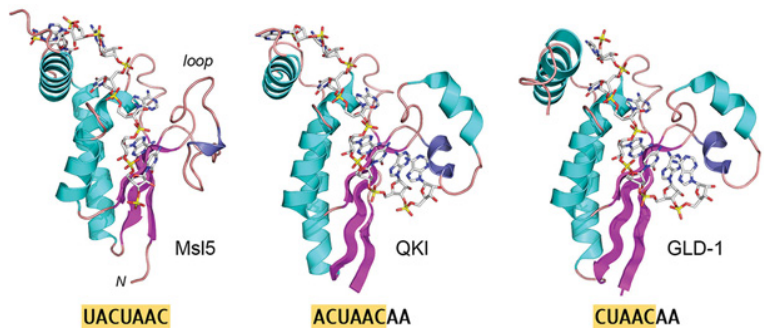

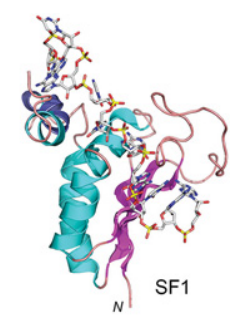

UAUACUAACAA
FIGURE 4. Comparison to other KH-QUA2 proteins. The tertiary structures of the KH-QUA2 domains of Ms15, QKI (pdb JVH), GLD-1 (pdb 4JVY), and SF1 (pdb 1K1G) were aligned and then offset horizontally. The RNA ligands are depicted as stick models. The nucleobase sequences of the RNAs are shown below the structures; positions of identity with respect to the yeast consensus branchpoint are shaded in gold. adopting a C3' endo sugar pucker; the six other ribose sugars have $\mathrm{C} 2{ }^{\prime}$ endo pucker. The interface entails an extensive network of direct and water-mediated hydrogen bonds from Msl5 to the RNA phosphates, ribose sugars, and nucleobase edges and a plethora of van der Waals contacts to the nucleosides. These include (i) interactions with the base edges that account for branchpoint sequence recognition; and (ii) contacts with the ribose $2^{\prime}-\mathrm{OH}$ groups that may explain discrimination of RNA versus DNA. The contacts are compiled in Supplemental Table S3 for each amino acid at the RNA interface. In addition, the branchpoint RNA itself makes intramolecular interactions between nucleobase and phosphate groups that stabilize a proper RNA conformation at the Msl5 interface. In this section, we highlight the contacts of the RNA nucleotides, proceeding from $5^{\prime}$ to $3^{\prime}$ along the branchpoint sequence, as follows.

Msl5 binding to the first 3 nt of the consensus branchpoint element is mediated via the QUA2 module (Fig. 5A). Arg253 coordinates the $\mathrm{pU}^{1} 5^{\prime}$-phosphate. The $\mathrm{U}^{1}$ nucleobase receives an edge-specific hydrogen bond to the uracil $\mathrm{O} 4$ carbonyl from the Asn249 main chain amide; this interaction should favor discrimination of uracil versus cytosine at this branchpoint position. $\mathrm{U}^{1}$ receives a second edge-specific hydrogen bond to the $\mathrm{O} 2$ carbonyl from Lys $252 \mathrm{~N} \zeta$. Lys 252 also donates a hydrogen bond to the cytosine $\mathrm{O} 2$ carbonyl of the $\mathrm{C}^{3}$ nucleobase. These features of the crystal structure neatly explain the results of Garrey et al. (2008), who reported that the Lys252-Arg253 dipeptide of yeast Msl5 (which differs from the corresponding Arg240-Lys241 dipeptide in human SF1) is a key determinant of the distinctive high RNA affinity and sequence specificity of Msl5 versus SF1. The NMR structure of SF1 was not instructive on this front, insofar as the SF1 Arg240 residue is remote from the RNA (Liu et al. 2001).

Msl5 recognition of the $A^{2}$ adenine nucleobase is accomplished via a hydrogen bond from adenine N6 to the Arg267 main chain carbonyl (Fig. 5A). The adenine also receives van der Waals contacts to adenine N7 from the Arg267 main chain amide and the Thr265 main chain carbonyl, to N6 from Leu266 C8, and to C8 from the Thr265 main chain carbonyl (Fig. 5A). (There are no main chain contacts to the $\mathrm{A}^{2}$ adenine base in the SF1 structure.) These main chain.RNA interactions of the C-terminal loop of the QUA2 module are collectively essential in vivo, insofar as an incremental deletion of the ${ }^{264}$ GTLREDNRP ${ }^{272}$ segment of Msl5 is lethal, whereas alanine mutations of the Thr265 and Arg267 side chains are not (Chang et al. 2012). The Msl5 Ala260 $\mathrm{C} \beta$ makes a van der Waals contact to the $\mathrm{A}^{2}$ ribose $2^{\prime}-\mathrm{OH}$. Leu256, which is important for Msl5 function in vivo (Schwer et al. 2013), is surrounded by and makes van der Waals contacts to the $\mathrm{U}^{1}$ and $\mathrm{C}^{3}$ ribose sugars (Fig. 5A) 

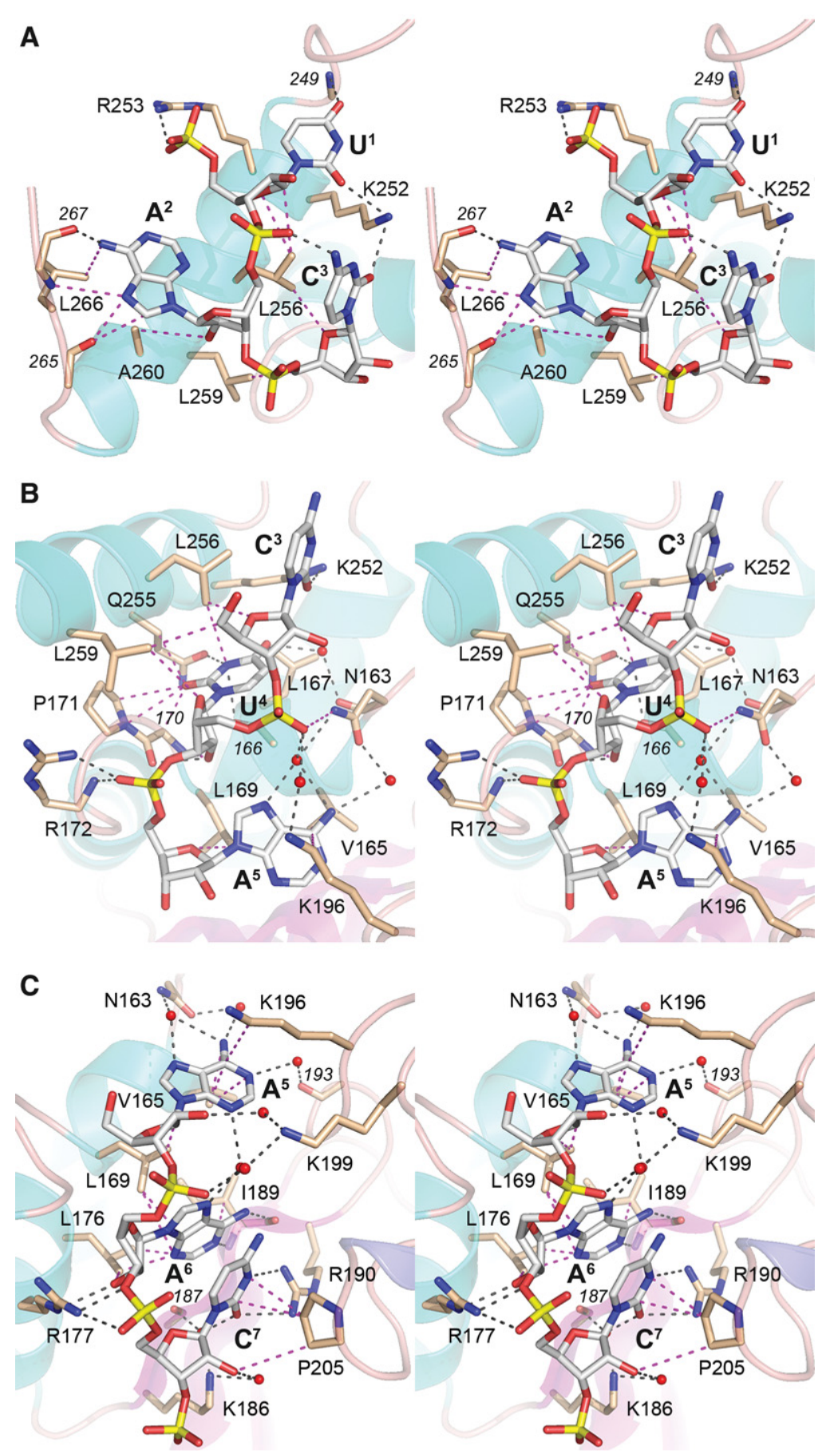

FIGURE 5. Atomic contacts of Msl5-(KH-QUA2) with the branchpoint RNA. Stereo views of the RNA binding site, highlighting atomic contacts to the branchpoint segments $\mathrm{U}^{1} \mathrm{~A}^{2} \mathrm{C}^{3}$ (in A), $C^{3} \mathrm{U}^{4} \mathrm{~A}^{5}$ (in $B$ ), and $\mathrm{A}^{5} \mathrm{~A}^{6} \mathrm{C}^{7}$ (in $C$ ). Amino acids and RNA are shown as stick models with beige and gray carbons, respectively. Waters are denoted by red spheres. Atomic contacts are indicated by dashed lines, in black for hydrogen bonds and magenta for van der Waals contacts.

and the $\mathrm{U}^{4}$ nucleobase (Fig. 5B). In a nice example of an internal RNA-RNA interaction of the Msl5-bound branchpoint element, the $\mathrm{U}^{1} \mathrm{pA}^{2}$ phosphate accepts a hydrogen bond from the $\mathrm{N} 4$ amine of the $\mathrm{C}^{3}$ pyrimidine nucleobase. This RNA-RNA interaction favors discrimination of cytosine versus uracil at the $\mathrm{C}^{3}$ position, i.e., a uracil $\mathrm{O} 4$ carbonyl would clash with the $\mathrm{U}^{1} \mathrm{pA}^{2}$ phosphate.

The $\mathrm{U}^{4}$ nucleobase donates hydrogen bonds from the $\mathrm{N} 3$ atom (protonated in uracil) to Gln255 Oe and the Gly166 main chain carbonyl; these contacts can account for Msl5 discrimination against a cytosine nucleobase at this position (Fig. 2D), i.e., because cytosine has an unprotonated $\mathrm{N} 3$ atom. In addition, $\mathrm{U}^{4}$ makes a water-bridged hydrogen bond from uracil $\mathrm{O} 4$ to the Asn 163 main chain carbonyl (Fig. 5B). The U4 base receives multiple van der Waals contacts: to $\mathrm{O} 2$ from Gln255, Gly170, and Pro171; and to $\mathrm{O} 4$ from Leu267 $\mathrm{C} \delta$. The $\mathrm{C}^{3} \mathrm{pU}^{4}$ phosphate makes a network of water-mediated hydrogen bonds to the N7 and N6 atoms of the $\mathrm{A}^{5}$ adenine nucleobase, to Lys196 $\mathrm{N \zeta}$, and to Asn163 Nס (Fig. 5B). Asn163 O $\delta$ makes an additional water-bridged hydrogen bond to the $\mathrm{A}^{5}$ nucleobase. Leu259, which is essential for Msl5 function in vivo (Schwer et al. 2013), makes van der Waals contacts via $C \delta$ to the $\mathrm{C}^{3}$ and $\mathrm{U}^{4}$ ribose sugars (Fig. $5 \mathrm{~B}$ ). The ribose $2^{\prime}-\mathrm{OH}$ of the $\mathrm{U}^{4}$ nucleoside makes a hydrogen bond to the Gly170 main chain $\mathrm{O}$ and a van der Waals contact to the Gly170 main chain $\mathrm{N}$. The $\mathrm{U}^{4} \mathrm{pA}^{5}$ phosphate is engaged by the side chain and main chain amide of Arg172 (Fig. 5B), a conserved residue essential for Msl5 activity in vivo (Schwer et al. 2013).

In addition to the water-mediated contacts to the $\mathrm{A}^{5}$ adenine edge atoms (which are purine specific but do not distinguish adenine from guanine), the purine ring is sandwiched on either side by van der Waals contacts to the Val165 and Lys196 side chains (Fig. 5C). Lys199 makes water-bridged hydrogen bonds to the $\mathrm{A}^{5}$ ribose $2^{\prime}-\mathrm{OH}$ and the $\mathrm{A}^{5} \mathrm{pA}^{6}$ phosphate. Leu169 makes van der Waals contacts to the $A^{5}$ ribose sugar.

Msl5 specifically recognizes the $A^{6} p$ nucleotide that defines the branchpoint via adenine-specific hydrogen bonds to the $\mathrm{A}^{6}$ nucleobase: from the Ile189 main chain amide to adenine $\mathrm{N} 1$ and from adenine N6 to the Ile189 main chain carbonyl (Fig. 5C). The same branchpoint adenine to main chain contacts are seen in the SF1 NMR structure (Liu et al. 2001). These are supplemented in Msl5 by edge-on van der Waals contacts to the $\mathrm{A}^{6}$ adenine 
N9 atom from Leu176 and to N1 from Ile189, and by hydrophobic stacking of Leu169 over the planar face of the purine ring, opposite the base stack of $A^{6}$ on $C^{7}$ (Fig. $5 C$ ). The $A^{6}$ adenine $\mathrm{N} 7$ atom makes an additional water-bridged hydrogen bond to the $\mathrm{N} 3$ atom of the $\mathrm{A}^{5}$ nucleobase (Fig. $5 \mathrm{C}$ ). The $\mathrm{A}^{6}$ ribose $2^{\prime}-\mathrm{OH}$ (the nucleophile in the first transesterification step of splicing) and the vicinal $\mathrm{A}^{6} \mathrm{pC}^{7}$ phosphate are both coordinated by the Arg177 side chain (Fig. 5C).

Finally, the $\mathrm{C}^{7}$ nucleobase is recognized via bidentate hydrogen bonding from the Arg190 terminal guanidinium nitrogens to the $\mathrm{O} 2$ and $\mathrm{N} 3$ atoms of the pyrimidine ring (Fig. 5C). Arg190 is essential for Msl5 function in vivo (Schwer et al. 2013). The $\mathrm{C}^{7} \mathrm{O} 2$ atom also makes water-bridged hydrogen bonds to Lys186 N $\zeta$ and the Ile187 main chain carbonyl. Pro205 packs against the face of the $\mathrm{C} 7$ pyrimidine ring opposite the base-stack with $\mathrm{A}^{6}$. The $\mathrm{C}^{7}$ ribose $2^{\prime}-\mathrm{OH}$ makes a water-mediated hydrogen bond with Lys186 N $\zeta$ and a van der Waals contact to Pro205 (Fig. 5C). The 3'phosphate at the end of the modeled RNA ligand makes a van der Waals contact with Lys186 Ce.

\section{Lethal alanine mutations efface or weaken branchpoint RNA binding in vitro}

Of the many constituents of the RNA interface of Msl5, only four amino acid side chains-Arg172, Arg190, Leu256, and Leu259-were found to be essential per se for Msl5 function in vivo, as gauged by the lethality of single alanine substitutions (Schwer et al. 2013). Here we introduced single R172A, R190A, L256A, and L259A changes into the Msl5(KH-QUA2) domain, produced the mutated proteins in bacteria and then purified them from soluble extracts in parallel with wild-type Msl5-(KH-QUA2) (Fig. 6A). The solubility of the recombinant alanine mutants, and their gel filtration profiles in the final purification step, were indistinguishable from
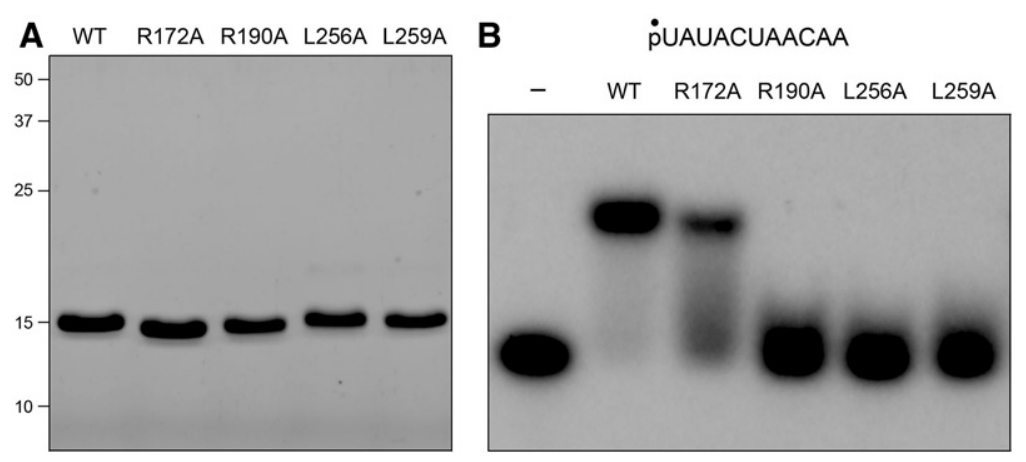

FIGURE 6. Effects of lethal alanine mutations on branchpoint RNA binding. (A) Aliquots ( $3 \mu \mathrm{g})$ of purified recombinant wild-type (WT) Msl5-(KH-QUA2) and the R172A, R190A, L256A, and L259A mutants were analyzed by SDS-PAGE. The Coomassie blue-stained gel is shown. The positions and sizes $(\mathrm{kDa})$ of marker polypeptides are indicated at left. $(B)$ RNA binding reaction

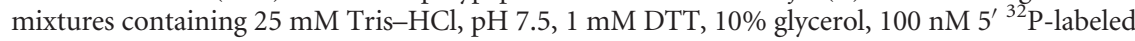
11-mer RNA as specified, and either no protein (-) or $500 \mathrm{nM}$ wild-type or mutants Msl5-(KHQUA2) as specified were incubated at $4^{\circ} \mathrm{C}$ for $20 \mathrm{~min}$. The mixtures were analyzed by native PAGE. An autoradiograph of the gel is shown. the wild-type protein (not shown). Native PAGE was used to assay binding of each protein to the $5^{\prime}{ }^{32} \mathrm{P}$-labeled 11 -mer RNA containing the consensus branchpoint sequence (Fig. 6B). Whereas wild-type Msl5-(KH-QUA2) shifted the RNA probe in high yield to form a discrete Msl5.RNA complex of retarded mobility, we detected little or no RNA binding to the R190A, L256A, and L259A mutants. The R172A mutation reduced the yield of the discrete Msl5.RNA complex and accumulated a diffuse smear of radiolabeled material between complex and the free RNA, indicative of dissociation during the PAGE procedure.

\section{Comparison to other RNA-bound KH-QUA2 proteins}

QKI and GLD-1 recognize consensus 6-nt RNA sequencesACUAAY (where $Y$ is pyrimidine) and UACUAA, respectively -that overlap with 6 of the $7 \mathrm{nt}$ in the consensus yeast intron branchpoint element UACUAAC. Indeed the RNA ligands in the Msl5, QKI, and GLD-1 crystal structures (Teplova et al. 2013) and the SF1 NMR structure (Liu et al. 2001) all contain the same core RNA sequence, corresponding to $\mathrm{C}^{3} \mathrm{U}^{4} \mathrm{~A}^{5} \mathrm{~A}^{6} \mathrm{C}^{7}$ in the yeast branchpoint (highlighted in yellow in Fig. 4). The conformation of the ACUAAC RNA segment bound to QKI is virtually identical to that of $\mathrm{A}^{2} \mathrm{C}^{3} \mathrm{U}^{4} \mathrm{~A}^{5} \mathrm{~A}^{6} \mathrm{C}^{7}$ bound to Msl5 when the two complexes are superimposed. The QKI and GLD-1 complexes include a 3 '-terminal ApA dinucleotide in a base-stacked conformation that abuts the variable loop (Fig. 4). The equivalent ApA segment was present in the Msl5 RNA ligand but was disordered in the structure. The variable loop adopts a more closed conformation in Msl5 than that seen in QK1 and GLD-1, such that the Msl5 loop $3_{10}$ helix clashes with the QKI/GLD-1 RNA 3'-terminal ApA dinucleotide when the structures are superimposed. In the SF1 structure, the adenine nucleobases of the $3^{\prime}$ ApA dinucleotide do not stack, but are splayed wide apart in a nearly orthogonal arrangement of the planar purine ring systems, the effect of which is to displace the $\mathrm{SF} 1$ variable loop to a more open configuration vis-à-vis Msl5.

Despite the functional orthology of yeast Msl5 and human SF1 in premRNA splicing, there are noteworthy differences in the conformation and path of the branchpoint RNA ligands in the structures of the respective KH-QUA2 modules, especially at the $5^{\prime}$ terminus of the UACUAAC branchpoint sequences present in both structures. Whereas the N6 atoms of the $\mathrm{A}^{5}$ adenine nucleobases are separated by only $1.6 \AA$ when the Msl5 and SF1 structures are superimposed, and the $\mathrm{N} 6$ atoms of the $\mathrm{A}^{6}$ adenine nucleobases are only $1.5 \AA$ apart, the N6 atoms of the $A^{2}$ adenine nucleobases are separated by $7 \AA$ and the $\mathrm{O} 4$ atoms of the $\mathrm{U}^{1}$ 
nucleobases are $17 \AA$ apart. Whereas the $\mathrm{U}^{1}$ nucleotide makes several specific contacts to Msl5 in the crystal structure, there are no apparent contacts to $\mathrm{U}^{1}$ in the SF1 NMR structure. At the $3^{\prime}$ end of the branchpoint element, the essential contact of yeast Msl5 Arg190 with the $C^{7}$ nucleobase (Fig. 5C) is not observed for the equivalent Arg178 residue of SF1. The upshot of the structural comparison is that the suite of atomic contacts of human SF1 with the branchpoint sequence observed in the NMR structure is not entirely portable to yeast Msl5.

In this vein, it is also worth underscoring that the present $1.8 \AA$ crystal structure of the Msl5.RNA complex affords the most complete picture to date of the interface of a KH-QUA2 protein with its RNA target site, especially with respect to the network of water-mediated protein-RNA and RNA-RNA contacts, which are not appreciable in the lower-resolution crystal structures of QKI $(3.5 \AA)$ and GLD-1 (2.85 $\AA)$ (Teplova et al. 2013).

\section{New structure-guided mutagenesis of Msl5 and synthetic genetic interactions}

Guided by the Msl5 crystal structure, we tested the effects of single alanine substitutions for four amino acids at the RNA interface: Arg177, Lys186, Pro205, and Gln255. We also introduced alanine mutations of two amino acids in the QUA2 a helix, Arg257 and Asn263, that do not make contact with the branchpoint RNA. Asn263 is conserved in SF1, QK1, and GLD-1; Arg257 is conserved in SF1 (Fig. 3C). Plasmid shuffle assays showed that all six MSL5-Ala alleles complemented the msl5 strain. R177A, K186A, P205A, R257A, and N263A cells grew as well as wild-type MSL5 cells on YPD agar at all temperatures tested, from $18^{\circ} \mathrm{C}$ to $37^{\circ} \mathrm{C}$, as gauged by colony size. In contrast, the Q255A allele elicited a tight cold-sensitive growth defect (Supplemental Fig. S2).

We then queried the new MSL5-Ala alleles for synthetic genetic interactions with null alleles of three vegetatively inessential spliceosome components: the Mud1 and Nam8 subunits of the yeast U1 snRNP and the Mud2 subunit of the Ms15·Mud2 heterodimer. Q255A was unconditionally

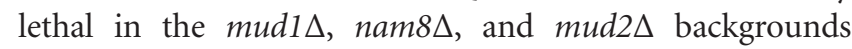
(Supplemental Fig. S2), thereby underscoring the importance of Gln255, identified in the crystal structure as a specificity determinant for recognition of the $\mathrm{U}^{4}$ nucleobase (Fig. 5B). The R177A, K186A, P205A, R257A, and N263A alleles supported wild-type growth in the nam $8 \Delta$ and mud $2 \Delta$ backgrounds (Supplemental Fig. S2). Whereas R177A, K186A, $P 205 A$, and $R 257 A$ displayed wild-type growth in a mud1 $\Delta$ background, the N263A mud1s strain was cold-sensitive (Supplemental Fig. S2).

\section{Mutations of Msl5 RNA-binding residues bypass the essentiality of Sub2}

Yeast Sub2 is an essential pre-mRNA splicing/export factor and a member of the DExD-box family of RNA-dependent
NTPases and RNA helicases (Libri et al. 2001; Zhang and Green 2001). Sub2 is implicated genetically in displacement of Msl5.Mud2 from the intron branchpoint during the transition from a pre-mRNA.U1·Msl5.Mud2 spliceosome to a pre-mRNA.U1.U2 spliceosome (Fig. 1A). Initial insights came from the observation that deletion of Mud2 could bypass the essentiality of Sub2 for vegetative growth (Kistler and Guthrie 2001), suggesting that the need for Sub2 during Msl5 ejection from the early spliceosome is alleviated when bridging contacts of Mud2 to the U1 snRNP are lost. The case was fortified by the finding that the essentiality of Sub2 for vegetative growth could also be bypassed by deletion of the N-terminal 56-aa segment of Msl5, which disrupts the interaction of Msl5 with Mud2 (Wang et al. 2008). We recapitulated both findings here, by testing mud2 $\triangle$ sub2 $\triangle \mathrm{p}$ [CEN URA3 SUB2] and $m s 15 \Delta$ sub2 $\Delta \mathrm{p}$ [CEN URA3 SUB2 MSL5] $\mathrm{p}$ [CEN HIS3 $M S L 5-\triangle N]$ strains for growth on FOA, which requires loss of the URA3 SUB2 plasmid. Ablation of Mud2, or deletion of the N-terminal 54-aa or 68-aa of Msl5, allowed growth on FOA in the absence of Sub2. Note that growth of the surviving $m u d 2 \Delta$ sub $2 \Delta$ and $m s l 5 \Delta$ sub2 $2 \mathrm{p}[M S L 5-\Delta N]$ bypass strains on YPD agar medium was slower than that of the corresponding SUB2 strain, as gauged by colony size (Fig. 1B).

The key question we address here is whether mutations of Msl5 amino acids that directly contact the RNA branchpoint might also bypass sub2 $\Delta$. We introduced a collection of viable MSL5 RNA binding site mutant alleles, on CEN HIS3 plasmids, into msl5 sub2 $2 \mathrm{p}$ [CEN URA3 SUB2 MSL5] cells and tested the $\mathrm{His}^{+}$transformants for growth on FOA. Three Msl5 mutants passed this test: L169A, I189A, and Q255A. The viable sub2 $\Delta$ cells bearing these bypass MSL5 alleles were tested for growth on YPD agar and found to be as effective as $m u d 2 \Delta$ in supporting growth of $s u b 2 \Delta$ cells at $34^{\circ} \mathrm{C}$ (Fig. $1 B)$. We conclude that specific hypomorphic mutations at the interface of Msl5 with the branchpoint can circumvent the need for Sub2 to displace Msl5 so that U2 snRNP can engage.

\section{Mutations of MsI5 RNA-binding residues affect splicing of specific pre-mRNAs}

Because Msl5 is essential in budding yeast, and because mutational analyses of the yeast intron branchpoint have focused almost exclusively on base-pairing interactions with the U2 snRNP, there is little known about the necessity of Msl5.branchpoint interactions in pre-mRNA splicing in vivo. Indeed, despite the plethora of synthetic lethal interactions between benign Msl5 mutations and equally benign mutations in the protein and U1 snRNA components of the early spliceosome (Chang et al. 2012; Qiu et al. 2012; Schwer et al. 2013), it has been problematic to demonstrate a direct role for Msl5 during splicing in vitro, either by depleting Msl5 from a yeast extract or preparing extracts from temperature-sensitive msl5 mutants (Rutz and Séraphin 1999, 2000). Here we exploited our collection of vegetatively benign 
mutations at the Msl5 RNA interface to interrogate the effects of perturbing particular Msl5.branchpoint contacts on the efficacy of splicing of specific yeast pre-mRNAs in vivo.

We initially surveyed two transcripts: GLC7, which has a single intron and is very efficiently spliced in wild-type cells (Fig. 7C); and SUS1, a two-intron-containing transcript (Fig. 7A). We chose SUS1 in light of our prior studies showing that (i) SUS1 splicing is adversely affected by a vegetatively benign Cbc2-Y24A mutation of the cap-binding pocket of yeast nuclear cap-binding complex (CBC) and (ii) the $C B C 2$ $Y 24 A$ allele is synthetically lethal or severely sick with benign MSL5 RNA binding site mutations N163A-V165A, V195AK196A, T265A-R267A, and K252A-R263A (Qiu et al. 2012). SUS1 is one of a few yeast genes that contain two introns and it is the splicing of the first intron (which has a non-consensus 5' splice site GUAUGA and a non-consensus branchpoint sequence UACUGAC) that is selectively impaired in the absence of CBC (Hossain et al. 2009). CBC is thought to bridge the pre-mRNA cap and the U1 snRNP during early spliceosome assembly.
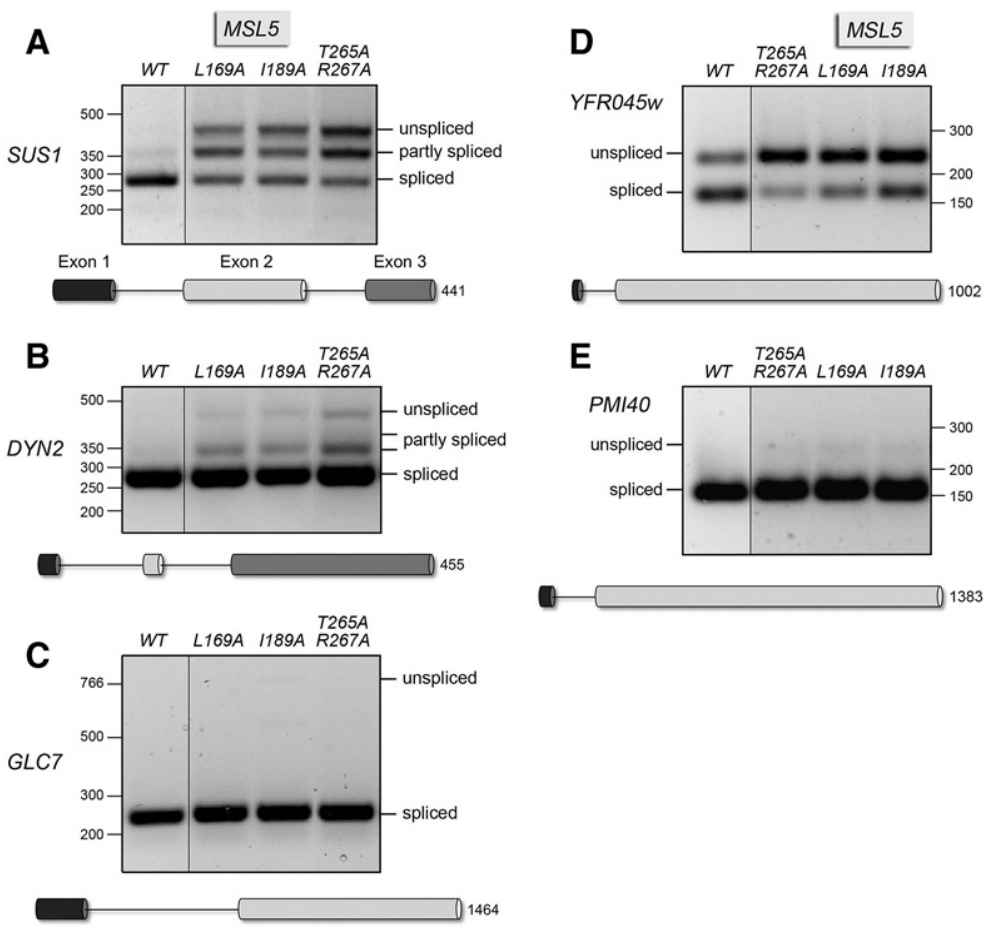

FIGURE 7. Mutations of Msl5 RNA-binding residues impede the splicing of specific premRNAs. RNA isolated from MSL5 wild-type (WT), L169A, I189A, and T265A-R267A cells was reverse transcribed with an oligo(dT) primer. cDNAs were PCR-amplified with gene-specific sense and antisense primer pairs derived from the first and last exons of the SUS1 (A), DYN2 (B), GLC7 (C), YFR045w (D), and PMI40 (E) genes. The exon-intron organization of the premRNA is shown, with exons depicted as horizontal cylinders. The PCR products were resolved by native agarose gel electrophoresis and visualized by staining with ethidium bromide. All lanes in the images are from the same gel and photographic exposure, from which intervening lanes were cropped and the WT lane was moved laterally to be next to $L 169 \mathrm{~A}$ and the T265A-R267A lane was moved laterally to be next to I189A. The positions and sizes (base pairs) of linear duplex DNA markers are indicated on the left. The RT-PCR products of unspliced, partly spliced, and fully spliced transcripts are specified.
cDNAs synthesized by oligo(dT)-primed reverse transcription of total RNA from yeast SKY strains with wildtype and mutant MSL5 alleles were PCR-amplified using gene-specific primer pairs flanking the first and last introns (see Supplemental Table S4), such that agarose gel electrophoresis would resolve the longer PCR fragments derived from unspliced pre-mRNA (which comigrates with the conrol fragment amplified from a genomic DNA template) and the case of SUS1, partially spliced intermediL169A, I189A, and T265A-R267A-that inhibited splicing of SUS1 (Fig. 7A) without affecting GLC7 splicing (Fig. C). As reported previously (Hossain et al. 2009; Qiu et al. predominantly of mature mRNA plus a minority intermediate species; unspliced pre-mRNA was not detected. In MSL5L169A, -I189A, and -T265A-R267A cells, the mature mRNA was diminished and the singly spliced intermediate and unspliced pre-mRNA together comprised the majority species (Fig. 7A).

Encouraged by these results, we surveyed the effects of Msl5 mutations on splicing of DYN2 pre-mRNA, which has two introns, each with consensus $5^{\prime}$ splice site and branchpoint sequences (Fig. 7B). Both DYN2 introns are efficiently removed in MSL5 wild-type cells and there is no detectable unspliced pre-mRNA. Although the mature DYN2 transcript was not grossly diminished in the L169A, $I 189 A$, and T265A-R267A strains, the interfacial mutations did elicit an increase in the levels of unspliced DYN2 transcript and in the singly spliced intermediate, in which, judging by the size of the PCR product, the proximal intron was spliced out but the distal intron was retained.

We also evaluated the effects of the Msl5 mutations on the splicing of two single-intron pre-mRNAs that have nonconsensus splicing signals. The PMI40 pre-mRNA, which has a non-consensus branchpoint sequence (AACUAAC), is spliced very efficiently in wild-type MSL5 cells and also in the L169A, I189A, and T265A-R267A mutants (Fig. 7E). In contrast, the YFR045w pre-mRNA, which has a non-consensus $5^{\prime}$ splice site GUAAGU and a non-consensus branchpoint sequence UAUUAAC, is relatively inefficiently spliced in wild-type cells, where the unspliced YFR045w precursor is evident, albeit less abundant than the spliced mature transcript (Fig. 7D). We 
found that YFR045w splicing was impeded in L169A, I189A, and T265A-R267A cells, in which the mature YFR045w mRNA was diminished and the unspliced pre-mRNA was the majority species in each mutant strain (Fig. 7D).

Finally, we tracked the splicing of the MATal pre-mRNA, which contains two introns, both with consensus splicing signals (Fig. 8). PCR amplification of the MATal cDNA with primers in exon 1 and exon 3 revealed efficient removal of both introns in wild-type cells, where the mature spliced mRNA was the predominant species, with comparatively little partially spliced intermediate and virtually no unspliced precursor (Fig. 8A). The L169A, I189A, and T265A-R267A mutations exerted a strong effect on MATa1 splicing, manifest by accumulation of singly spliced intermediate (the predominant species in $L 169 A$ and $I 189 A$ cells) and unspliced precursor, at the expense of mature spliced mRNA (Fig. 8A). To define which splicing steps were impacted by the Msl5 mutations, we performed PCR amplification of the MATal cDNA with intron and exon primer pairs. Intron 1 and exon 3 primers yielded scant amplification from wild-type cells of unspliced MATa1 precursor or the intermediate in which intron 2 was excised but intron 1 was retained (Fig. 8B). In contrast, these primers readily amplified unspliced precursor
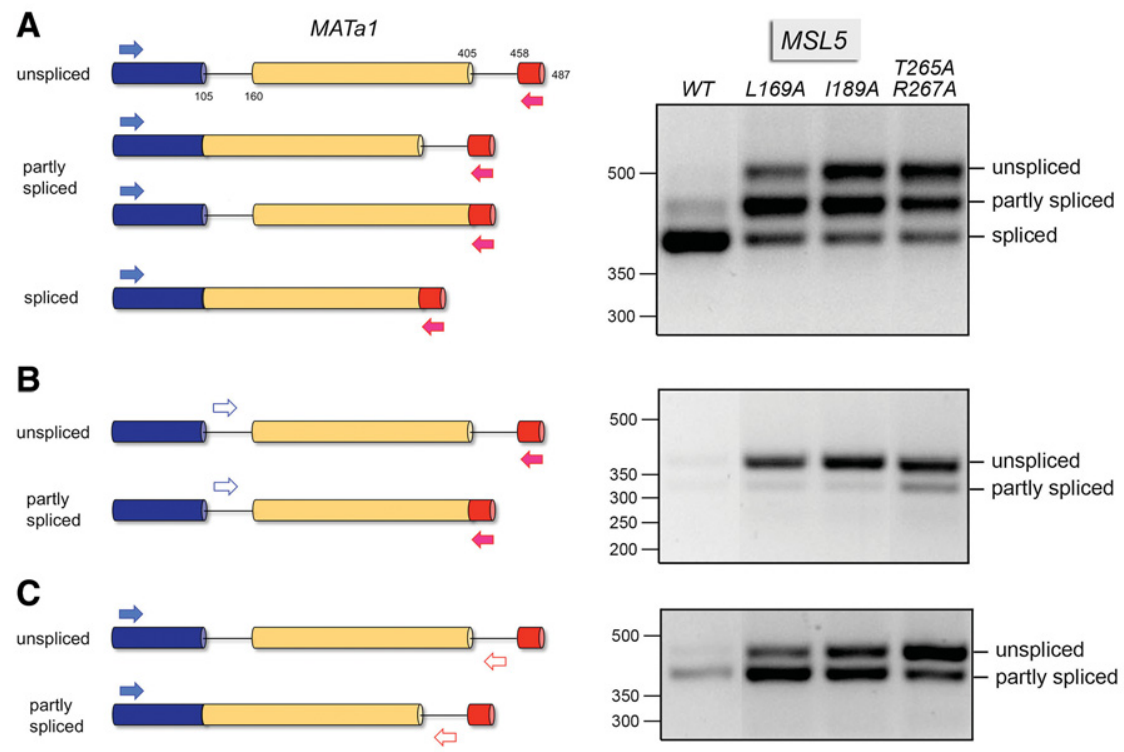

FIGURE 8. Effects of MSL5 mutations on MATa1 pre-mRNA splicing. The unspliced MATa1 pre-mRNA comprising three exons (depicted as horizontal cylinders with exon 1 in blue, exon 2 in gold, and exon 3 in red) and two introns, the two partly spliced intermediates with one intron retained, and the mature spliced mRNA are depicted on the left. RNA isolated from MSL5 wildtype (WT), L169A, I189A, and T265A-R267A cells was reverse transcribed with an oligo(dT) primer, and the MATal cDNAs were PCR-amplified with gene-specific primer pairs, depicted as forward and reverse arrows, in exon 1 and exon $3(A)$, intron 1 and exon $3(B)$, or exon 1 and intron $2(C)$. The PCR products were resolved by native agarose gel electrophoresis and visualized by staining with ethidium bromide. All lanes in the image are from the same gel and photographic exposure, from which intervening lanes were cropped and the $W T$ lane was moved laterally to be next to $L 169 A$; the T265A-R267A lane was moved laterally to be next to I189A. The positions and sizes (bp) of linear duplex DNA markers are indicated on the left. The positions of the RT-PCR products of unspliced, partly spliced, and fully spliced MATa1 are indicated at right. from $L 169 A$, I189A, and T265A-R267A cells. In the $L 169 A$ T265A-R267A cells (Fig. 8B). Exon 1 and intron 2 primer pairs detected in wild-type cells the singly spliced intermediate in which intron 1 was excised but intron 2 was not (Fig. . The salient finding was that this intermediate accumuthe unspliced precursor was the major species amplified by the exon 1 and intron 2 primers, though the singly spliced intermediate was still elevated compared with wild-type (Fig. $8 \mathrm{C})$. These results indicate that the T265A-R267A allele impeded the splicing of both introns of the MATal pre-mRNA.

\section{DISCUSSION}

The elucidation at atomic resolution of the interface of Msl5 with the yeast intron branchpoint sequence UACUAAC, married with structure-guided mutagenesis of the amino acids that comprise the interface, firmly establishes Msl5 as decisive for pre-mRNA splicing in vivo. The KH-QUA2 module of Msl5 that suffices for intron recognition exemplifies a family of structurally homologous RNA binding proteins, with overlapping target site specificities, that participate in diverse cellular RNA transactions (Teplova et al. 2013). Msl5 and human SF1 are orthologous branchpoint-binding splicing factors with distinctive site specificities and affinities that correlate with the conservation (in yeast) or diversity (in humans) of native intron branchpoint sequences. Whereas Msl5 is sensitive to perturbations of the $\mathrm{U}^{1} \mathrm{~A}^{2} \mathrm{C}^{3}$ and $\mathrm{C}^{7}$ nucleobases of the consensus branchpoint, SF1 is not (Berglund et al. 1997; Garrey et al. 2008). The NMR structure of SF1 bound to a yeast consensus branchpoint RNA illuminated the principles of RNA recognition by KH-QUA2 proteins (Liu et al. 2001), but not the basis for the functional differences between the yeast and human orthologs.

The present Msl5 crystal structure reveals an extensive network of direct and water-mediated protein-RNA and intraRNA atomic contacts that explain how Msl5 recognizes (and in most cases discriminates) each nucleobase of the 
UACUAAC element. Comparison to SF1 highlights key differences in the secondary structure, position, and amino acid sequence of the QUA2 module that help rationalize the different stringencies of recognition of the $\mathrm{U}^{1} \mathrm{~A}^{2} \mathrm{C}^{3}$ nucleobases. These structural insights are in keeping with biochemical studies of chimeric Msl5-SF1 proteins that implicated the QUA2 module, and its Lys252-Arg253 dipeptide, as determinants of Msl5 target specificity and affinity in vitro (Garrey et al. 2008). Yet, this dipeptide is clearly not decisive per se for Msl5 function in vivo, insofar as a yeast MSL5-(K252A-R253A) strain grows as well as wild-type MSL5 cells at $25^{\circ} \mathrm{C}-37^{\circ} \mathrm{C}$ (Chang et al. 2012). However, the K252A-R253A allele is synthetically lethal in combination with otherwise benign nam $8 \Delta$, tgs $1 \triangle$, and $C B C 2-Y 24 A$ alleles (Chang et al. 2012; Qiu et al. 2012), signifying that the effects on growth of subtracting specific atomic contacts of the QUA2 module with the $\mathrm{U}^{1}$ and $\mathrm{C}^{3}$ nucleobases (via Lys252) and the $\mathrm{U}^{1} \mathrm{pA}^{2}$ phosphate (by Arg253) are genetically buffered by other components of the early spliceosome. It is noteworthy that the two constituents of the QUA2 module that are important per se for in vivo activity, Leu256 and Leu259 (Schwer et al. 2013), make van der Waals contacts to the $\mathrm{U}^{1}$ ribose, $\mathrm{C}^{3}$ ribose, and $\mathrm{U}^{4}$ nucleoside (Fig. $5 \mathrm{~A}, \mathrm{~B}$ ) that shape the trajectory and conformation of the branchpoint RNA. As we show here (Fig. 6), subtracting the Leu256 and Leu269 contacts by alanine mutation effaced Msl5-(KH-QUA2) binding to the yeast branchpoint RNA in vitro.

The Msl5 structure also indicates how differences in the conformation and contacts of the variable loop of the $\mathrm{KH}$ module might explain the distinctive stringencies of Msl5 and SF1 for the $\mathrm{C}^{7}$ nucleobase. In the SF1-RNA complex there are no base-specific contacts to $C^{7}$, just a van der Waals interaction with Val183 in the variable loop (Liu et al. 2001). The cytosine nucleobase is sandwiched in a basestack between $\mathrm{A}^{6}$ and $\mathrm{A}^{8}$, and the $\mathrm{C}^{7}$ ribose sugar has a $\mathrm{C}^{\prime}$ endo pucker. In the Msl5.RNA complex, the $\mathrm{C}^{7}$ ribose adopts a $\mathrm{C}^{\prime}$ endo pucker. The $\mathrm{C}^{7}$ nucleoside packs closely against Pro205 in a closed conformation of the variable loop. Arg190 (in the $\beta 2$ strand, immediately preceding the loop) makes specific contacts with $C^{7}$ (Fig. 5C) that are essential per se for Msl5 activity in vivo and in vitro, i.e., R190A is lethal (Schwer et al. 2013) and the R190A mutation eliminates binding of Msl5-(KH-QUA2) to the consensus yeast branchpoint RNA (Fig. 6).

The Msl5 crystal structure enables coherent interpretation of an extensive alanine mutagenesis of amino acids at the RNA interface (Chang et al. 2012; Qiu et al. 2012; Schwer et al. 2013; data herein). Whereas relatively few Msl5 interfacial mutations affect yeast vegetative growth, many of them exert lethal effects in tandem with mutations in other components of the early spliceosome, especially U1 snRNP subunits Nam8 and Mud1 and the Mud2 subunit of the yeast branchpoint binding protein complex. The assumption that the hypomorphic Msl5 KH-QUA2 mutations weaken the inter- action of the Msl5.Mud2 heterodimer with intron branchpoint in vivo is validated in the present study by two key findings: (i) that certain interfacial mutations bypass the essentiality of Sub2 and (ii) that interfacial mutations impede the splicing of specific yeast pre-mRNAs.

Sub2, the yeast ortholog of mammalian UAP56 (Zhao et al. 2004; Shen et al. 2007), is an essential DExD-box protein that drives a conformational switch in the spliceosome, whereby Msl5.Mud2 exits the branchpoint to allow ingress of the U2 snRNP (Fig. 1). Our finding that three interfacial mutant alleles in our collection bypass sub2 $\Delta$, together with earlier observations that elimination of Mud2 or the Mud2 interaction domain of Msl5 also bypass sub2 (Kistler and Guthrie 2001; Wang et al. 2008), indicate that the bridging interactions between U1 snRNP and the Mud2 subunit of the Msl5.Mud2 complex and the protein-RNA contacts of the Msl5 KH-QUA2 domain of the Ms15·Mud2 complex provide distinct, but genetically redundant, stabilizing forces within the pre-mRNA.U1·Msl5.Mud2 spliceosome that dictate the need for Sub2. The theme of genetic redundancy is highlighted by the fact that the L169A, I189A, and Q255A mutations in the Msl5 RNA binding site are each synthetically lethal with mud2 $\Delta$ (Supplemental Fig. S2; Chang et al. 2012). The allele specificity of sub2 $2 \Delta$ bypass by MSL5-Ala mutants implicates (for the first time, to our knowledge) specific RNA contacts as governors of the Sub2 requirement for Ms15.Mud2 displacement from the branchpoint. Leu169 and Ile189 together engage the $A^{5}$ nucleoside and the $A^{6}$ nucleobase (Fig. 5C). Gln255 coordinates the $\mathrm{U}^{4}$ nucleobase (Fig. 5B).

In the same vein, we establish here (also for the first time, to our knowledge) that specific branchpoint RNA contacts of Msl5 govern the splicing of specific yeast pre-mRNAs in vivo. It has been appreciated for some time that the yeast premRNA splicing apparatus is not monolithic in its handling of intron-containing RNAs. For example, studies of RNA processing during the yeast meiotic developmental program have uncovered a shift in the splicing patterns of specific meiotic pre-mRNAs from a vegetative "off" state, in which single introns are included, to a meiotic "on" state in which the target introns are removed. The efficiency of meiotic intron removal is either regulated or governed by the actions of splicing factors or RNA modifying enzymes that are inessential for vegetative growth (e.g., Mer1, Nam8, Tgs1, Cbc2) (Engebrecht et al. 1991; Spingola and Ares 2000; Munding et al. 2010; Qiu et al. 2011a,b,c, 2012). In addition, comparative genome-wide profiling of vegetative RNA splicing in wild-type and mutant strains deleted for inessential splicing factors, or in conditional mutants of essential factors after shift to restrictive temperature, has fortified the theme that yeast splicing factors are differentially dedicated to splice particular pre-mRNA “clients" (Pleiss et al. 2007; Albulescu et al. 2012).

Here we identified four yeast pre-mRNAs (SUS1, DYN2, YFR045w, and MATa1) as specific clients of Msl5, whereby their vegetative splicing is impeded by specific hypomorphic 
alanine mutations in the branchpoint RNA binding site of the KH-QUA2 domain. The L169A, I189A, and T265A-R267A alleles that elicit the transcript-specific splicing defects in vivo do so without having an overt impact on yeast vegetative growth at $25^{\circ} \mathrm{C}-37^{\circ} \mathrm{C}$ (Chang et al. 2012; Schwer et al. 2013). Thus, the contributions of the contacts of these amino acids with the intron branchpoint to gene-specific splicing can be gauged and interpreted (based on the crystal structure) without the complications inherent in (i) relying on shifting a cs or ts mutant in an essential splicing factor to restrictive growth temperatures and (ii) deriving mechanistic insights from $c s$ and ts amino acid changes, which rarely provide a clean structure-activity relationship.

The MSL5-Ala effects on SUS1, YFR045w, and MATa1 splicing are significant, entailing both a decrease in the level of mature spliced RNA and an increase in the abundance of unspliced precursor and, in the case of the two-intron transcripts, singly spliced intermediate. In the case of the DYN2 transcript, the partially spliced intermediate was seen in the mutants, but the level of mature spliced DYN2 mRNA was undiminished. It is worth noting that the SUS1, YFR045w, MATa1, and DYN2 genes are inessential for yeast vegetative growth. The selectivity of the MSL5-Ala client roster is underscored by the findings that these same mutations had no impact on the splicing of intron-containing transcripts of the essential GLC7 and PMI40 genes. Although our sample size is small at this stage, it appears that an intron with both a non-consensus branchpoint and a non-consensus $5^{\prime}$ splice site is vulnerable to the effects of the MSL5-Ala interfacial mutations. A full delineation of the Msl5 roster will require profiling by genome-wide RNA sequencing the splicing patterns in our extensive collection of viable hypomorphic MSL5 mutants.

\section{MATERIALS AND METHODS}

\section{Purification of Msl5-(144-271)}

A 384-nt DNA fragment encoding the KH-QUA2 domain (amino acids 144-271) of yeast Msl5 was amplified from Saccharomyces cerevisiae genomic DNA by PCR with primers that introduced a BamHI site at the start codon and an XhoI site immediately after the stop codon. The PCR product was digested with BamHI and XhoI and inserted between the BamHI and XhoI sites of pET28b$\mathrm{His}_{10} \mathrm{Smt} 3$ to generate an expression plasmid encoding the Msl5 polypeptide fused to an N-terminal $\mathrm{His}_{10} \mathrm{Smt} 3$ tag. The pETHis $_{10}$ Smt3·Msl5-(144-271) plasmid was transfected into Escherichia coli BL21(DE3). A 4-L culture amplified from a single transformant was grown at $37^{\circ} \mathrm{C}$ in TB broth containing $50 \mu \mathrm{g} / \mathrm{mL}$ kanamycin and $0.4 \%(\mathrm{v} / \mathrm{v})$ glycerol until the $A_{600}$ reached 0.6 . The culture was chilled on ice for $1 \mathrm{~h}$, then adjusted to $2 \%(\mathrm{v} / \mathrm{v})$ ethanol and 0.3 $\mathrm{mM}$ isopropyl- $\beta$-D-thiogalactopyranoside, and incubated for $20 \mathrm{~h}$ at $17^{\circ} \mathrm{C}$ with constant shaking. All subsequent steps were performed at $4^{\circ} \mathrm{C}$. Cells were harvested by centrifugation and resuspended in 25 $\mathrm{mL}$ of buffer A (50 mM Tris-HCl, pH 7.5, $500 \mathrm{mM} \mathrm{KCl,} 15 \mathrm{mM}$ imidazole, $10 \%$ glycerol) containing one protease inhibitor cocktail tablet (Roche). The cells were lysed by sonication and the insoluble material was removed by centrifugation at $38,000 \mathrm{~g}$ for $30 \mathrm{~min}$. The supernatant was mixed for $1 \mathrm{~h}$ with $5 \mathrm{~mL}$ of His60-Ni Superflow resin (Clontech) that had been equilibrated with buffer A. The resin was recovered by centrifugation and resuspended in $50 \mathrm{~mL}$ of buffer A containing $2 \mathrm{M} \mathrm{KCl}$. The washed resin was centrifuged again, resuspended in $50 \mathrm{~mL}$ of buffer $\mathrm{A}$, and then poured into a column. The adsorbed $\mathrm{His}_{10} \mathrm{Smt} 3 \cdot \mathrm{Msl} 5-(144-271)$ was eluted with buffer A containing $300 \mathrm{mM}$ imidazole. The eluate was supplemented with Smt3-specific protease Ulp1 (at a Msl5:Ulp1 molar ratio of 1000:1) and then dialyzed overnight against 2 L of buffer B (20 $\mathrm{mM}$ Tris- $\mathrm{HCl}, \mathrm{pH} 7.5,100 \mathrm{mM} \mathrm{KCl}, 5 \%$ glycerol). The dialysate was applied to a 5-mL His60-Ni Superflow column that had been equilibrated with buffer B and the tag-free Msl5-(144-271) protein was recovered in the flow-through fraction. This material was applied to a prepacked 5-mL heparin-Sepharose column (GE Healthcare) equilibrated in buffer C (25 mM Tris-HCl, $\mathrm{pH} 7.5$, $2.5 \%$ glycerol, $1 \mathrm{mM} \mathrm{DTT}$ ) containing $100 \mathrm{mM} \mathrm{KCl}$. The column was eluted with a $75-\mathrm{mL}$ linear gradient of $0.1-1 \mathrm{M} \mathrm{KCl}$ in buffer C. Msl5-(144-271) eluted as a single component at $\sim 300 \mathrm{mM}$ $\mathrm{KCl}$. Peak fractions were pooled and subjected to gel filtration through a Superdex-200 column (GE Healthcare) equilibrated in $10 \mathrm{mM}$ Tris- $\mathrm{HCl}, \mathrm{pH} 8.0,150 \mathrm{mM} \mathrm{KCl}, 3 \mathrm{mM}$ DTT. The purified protein was stored at $-80^{\circ} \mathrm{C}$. Protein concentration was determined from the $A_{280}$ measured with a Nanodrop spectrophotometer (Thermo Scientific), applying a molar extinction coefficient of $4470 \mathrm{M}^{-1} / \mathrm{cm}$, as calculated by Protparam.

\section{Preparation of SeMet-Msl5-(144-271)}

The native KH-QUA2 module includes only one methionine (Met209). To facilitate structure determination by selenomethionine (SeMet) SAD methods, the native Ile222, Ile227, and Val238 side-chains were replaced with methionine. Methionine codons were introduced into the MSL5-(144-271) open reading frame of the pET-His ${ }_{10} \mathrm{Smt} 3 \cdot \mathrm{Msl5}-(144-271)$ plasmid by PCR amplification with mutagenic primers. The expression plasmid was transformed into E. coli B834(DE3). A single transformant was inoculated into $10 \mathrm{~mL}$ of LB medium containing $50 \mu \mathrm{g} / \mathrm{mL}$ kanamycin and incubated for $8 \mathrm{~h}$ at $37^{\circ} \mathrm{C}$. The bacteria were harvested by centrifugation and then resuspended in $200 \mathrm{~mL}$ of complete LeMaster medium containing $50 \mu \mathrm{g} / \mathrm{mL}$ kanamycin and $50 \mu \mathrm{g} / \mathrm{mL}$ SeMet (L-(+)-enantiomer; ACROS Organics). After overnight incubation, the culture volume was increased to $8 \mathrm{~L}$ with fresh LeMaster medium (+kanamycin + SeMet), and growth was continued at $37^{\circ} \mathrm{C}$ with constant shaking until the $A_{600}$ reached 0.6. The culture was placed on ice for $1 \mathrm{~h}$, adjusted to $0.3 \mathrm{mM}$ isopropyl- $\beta$-D-thiogalactoside and $2 \%$ ethanol, and then incubated for $18 \mathrm{~h}$ at $17^{\circ} \mathrm{C}$ with continuous shaking. Cells were harvested by centrifugation, and the pellet was stored at $-80^{\circ} \mathrm{C}$. The SeMet-Msl5-(144-271) protein was purified via the same procedure described above for native Msl5-(144271), except that the final storage buffer contained $5 \mathrm{mM}$ DTT.

\section{Crystallization}

Crystals of native and SeMet-substituted Msl5-(144-271) in complex with an 11-mer RNA oligonucleotide 5'-UAUACUAACAA containing a consensus yeast branchpoint sequence (underlined) were grown by the sitting drop vapor diffusion method at $22^{\circ} \mathrm{C}$. 
A mixture of 1.7 mM Msl5-(144-271) and 1.7 mM 11-mer RNA was incubated for $20 \mathrm{~min}$ at $22^{\circ} \mathrm{C}$. Aliquots $(2 \mu \mathrm{L})$ were then mixed with $2 \mu \mathrm{L}$ of reservoir buffer containing 2.1-2.3 M ammonium sulfate, $10 \mathrm{mM}$ magnesium acetate, $0.05 \mathrm{M}$ MES ( $\mathrm{pH}$ 5.6). Crystals grew to their full size within 7-10 d. Crystals were harvested, cryoprotected by transfer to a solution containing $3.2 \mathrm{M}$ ammonium sulfate, $10 \mathrm{mM}$ magnesium acetate, $0.05 \mathrm{M} \mathrm{MES} \mathrm{(pH} \mathrm{5.6),} \mathrm{5 \%} \mathrm{glycerol} \mathrm{and}$ then flash-frozen in liquid nitrogen.

\section{Structure determination}

Diffraction data for SeMet-Msl5-(144-271) at $2.2 \AA$ resolution were collected at the Se anomalous peak wavelength at the National Synchrotron Light Source beamline X25 equipped with Pilatus $6 \mathrm{M}$ detector. The SeMet-Msl5-(144-271) crystal belonged to space group P422 with unit cell dimensions consistent with one protomer per asymmetric unit, assuming a solvent content of 59\%. Indexing and merging of the diffraction data were performed in iMosflm and Scala, respectively. The structure was solved using single-wavelength anomalous dispersion (SAD) data from a single crystal. Location of four heavy atom sites corresponding to the SeMet residues, generation of electron density maps, and initial model building were accomplished with Autosol and Autobuild in Phenix (Adams et al. 2002). The initial maps showed clear density for most of the Msl5 amino acids and for a 7-mer RNA oligonucleotide. The structure was iteratively refined in Phenix and adjusted manually in Coot (Emsley and Cowtan 2004). The final refined $2.2 \AA$ model $\left(R / R_{\text {free }} 17.2 / 21.5\right)$, comprising a continuous Msl5 polypeptide from amino acids 145-271 and a 7-nt RNA 5'-UACUAAC, had excellent geometry and no Ramachandran outliers (Supplemental Table S1).

The native Msl5-(144-271) crystal belonged to space group P2 1 and diffracted to $1.8 \AA$ resolution. Unit cell dimensions were consistent with four to five protomers per asymmetric unit, assuming a solvent content of $47 \%-57 \%$. The native crystal was pseudo-merohedrally twinned with a twinning fraction of 0.5 . Phases were determined by molecular replacement in Phenix.Phaser using the SeMet-Msl5-(144-271) structure as a search model. The native crystal contained four Msl5-(144-271) protomers per asymmetric unit. The structure was iteratively refined (without NCS restraints) in Phenix with a twinning operator $(l,-k, h)$. Three of the four protomers comprised continuous polypeptides, from amino acids 145 to 268,145 to 270 , and 146 to 267 , respectively. The fourth protomer comprised two segments, from 147 to 197 and 204 to 266, punctuated by a 6 amino acid gap. Each protomer was bound to a 7 -mer RNA, $5^{\prime}$-UACUAAC. The final $1.8 \AA$ model refined to $R / R_{\text {free }}$ of 17.5/20.6 (Supplemental Table S1).

\section{MsI5 expression plasmids and mutants}

CEN plasmids bearing wild-type and mutated MSL5 genes under the control of the native MSL5 promoter have been described (Chang et al. 2012; Schwer et al. 2013). New missense mutations R177A, K186A, P205A, Q255A, R257A, and N263A were introduced into MSL5 by two-stage PCR overlap extension with mutagenic primers. The PCR products were digested and then inserted into the pRS413based MSL5 expression plasmid (Schwer et al. 2013). The MSL5 genes were sequenced completely to confirm that no unwanted changes were acquired during amplification and cloning.

\section{Yeast strains and tests of Msl5 function in vivo}

Plasmid shuffle assays for gauging mutational effects on MSL5 function in a msl5 $\Delta \mathrm{p}[C E N$ URA3 MSL5] strain and for synthetic genetic interaction with $m u d 2 \Delta$, nam $8 \Delta$, and mud1 $1 \Delta$ were performed as described previously (Chang et al. 2012; Schwer et al. 2013). To investigate genetic interactions of MSL5 mutants with the essential SUB2 gene, we first generated heterozygous msl5 $/$ MSL5 sub2 $\Delta /$ SUB2 diploids by crossing msl5A::natMX p360-MSL5 cells with sub2 $2:: k a n M X$ p316-SUB2 cells of the opposite mating type, selecting diploids on YPD medium containing G418 and clonNat and plating them to FOA-containing medium. The heterozygous diploids were then transformed with a CEN URA3 SUB2 MSL5 (p316-SUB2-MSL5) plasmid, in which the SUB2 gene ( -534 to $+2550)$ is arranged in a head-to-tail configuration with the MSL5 gene (2.2 kbp segment). $\mathrm{Ura}^{+}$heterozygous diploids were subjected to sporulation and tetrad dissection, after which haploid $m s l 5 \Delta$ sub2 $\Delta$ [p316-SUB2-MSL5] progeny were recovered. These cells were unable to grow on FOA medium, but the double-deletion strains could be complemented by cotransformation with $\mathrm{p}[C E N$ LEU2 SUB2] plus p[CEN HIS3 MSL5].

\section{RT-PCR assays of pre-mRNA splicing in vivo}

Diploid yeast SKY strains with homozygous chromosomal wildtype, L169A, I189A, or T265A-R267A MSL5 loci were grown in liquid YPD medium until $A_{600}$ reached 0.6-0.8. Cells (20 $A_{600}$ units) were harvested by centrifugation and total cellular RNA was isolated by using a MasterPure Yeast RNA Purification Kit (Epicentre BioTechnologies) according to the vendor's instructions. The RNA preparations were treated with DNase I. First-strand cDNA synthesis was carried out by using the SuperScript II Reverse Transcriptase Kit (Invitrogen) with $1 \mu \mathrm{g}$ of total RNA template and an oligo(dT) ${ }_{12-18}$ primer. PCR amplification (35 cycles) by PfuTurbo DNA polymerase (Agilent Technologies) of the MATa1, SUS1, DYN2, GLC7, YFR045w, and PMI40 cDNAs was primed by $0.2 \mu \mathrm{M}$ gene-specific sense and antisense strand oligonucleotides (Supplemental Table S4). The PCR products were resolved by electrophoresis through a native $2 \%$ agarose gel and visualized by staining with ethidium bromide.

\section{DATA DEPOSITION}

The coordinates for the SeMet and native Msl5-(KH-QUA2).RNA complexes have been deposited in the RCSB protein structure database under pdb ID codes $4 \mathrm{WAL}$ and $4 \mathrm{WAN}$.

\section{SUPPLEMENTAL MATERIAL}

Supplemental material is available for this article.

\section{ACKNOWLEDGMENTS}

This work was supported by National Institutes of Health (NIH) grants GM52470 (S.S.) and GM50288 (B.S.). S.S. is an American Cancer Society Research Professor.

Received November 6, 2014; accepted December 8, 2014. 


\section{REFERENCES}

Abovich N, Rosbash M. 1997. Cross-intron bridging interactions in the yeast commitment complex are conserved in mammals. Cell 89: 403-412.

Abovich N, Liao XC, Rosbash M. 1994. The yeast MUD2 protein: an interaction with PRP11 defines a bridge between commitment complexes and U2 snRNP addition. Genes Dev 8: 843-854.

Adams PD, Grosse-Kunstleve RW, Hung LW, Ioerger TR, McCoy AJ, Moriarty NW, Read RJ, Sacchettini JC, Sauter NK, Terwilliger TC. 2002. PHENIX: building new software for automated crystallographic structure determination. Acta Crystallogr D Biol Crystallogr 58: $1948-1954$.

Albulescu LO, Sabet N, Gudipati M, Stepankiw N, Bergman ZJ, Huffaker TC, Pleiss JA. 2012. A quantitative, high-throughput reverse genetic screen reveals novel connections between pre-mRNA splicing and $5^{\prime}$ and $3^{\prime}$ end transcript determinants. PLoS Genet 8: e1002530.

Berglund JA, Chua K, Abovich N, Reed R, Rosbash M. 1997. The splicing factor BBP interacts specifically with the pre-mRNA branchpoint sequence UACUAAC. Cell 89: 781-787.

Chang J, Schwer B, Shuman S. 2010. Mutational analyses of trimethylguanosine synthase (Tgs1) and Mud2: proteins implicated in premRNA splicing. RNA 16: 1018-1031.

Chang J, Schwer B, Shuman S. 2012. Structure-function analysis and genetic interactions of the yeast branchpoint binding protein Msl5. Nucleic Acids Res 40: 4539-4552.

Emsley P, Cowtan K. 2004. Coot: model-building tools for molecular graphics. Acta Crystallogr D Biol Crystallogr 60: 2126-2132.

Engebrecht JA, Voelkel-Meiman K, Roeder GS. 1991. Meiosis-specific RNA splicing in yeast. Cell 66: 1257-1268.

Garrey SM, Voelker R, Berglund JA. 2006. An extended RNA binding site for the yeast branch point-binding protein and the role of its zinc knuckle domains in RNA binding. J Biol Chem 281: 27443-27453.

Garrey SM, Cass DM, Wandler AM, Scanlan MS, Berglund JA. 2008. Transposition of two amino acids changes a promiscuous RNA binding protein into a sequence-specific RNA binding protein. RNA 14: 78-88.

Gottschalk A, Tang J, Puig O, Salgado J, Neubauer G, Colot HV, Mann M, Séraphin B, Rosbash M, Lührmann R, et al. 1998. A comprehensive biochemical and genetic analysis of the yeast U1 snRNP reveals five novel proteins. RNA 4: 374-393.

Holm L, Kääriäinen S, Rosenström P, Schenkel A. 2008. Searching protein structure databases with DaliLite v.3. Bioinformatics 24: 2780-2781.

Hossain MA, Claggett JM, Nguyen T, Johnson TL. 2009. The cap binding complex influences $\mathrm{H} 2 \mathrm{~B}$ ubiquitination by facilitating splicing of the SUS1 pre-mRNA. RNA 15: 1515-1527.

Kistler AL, Guthrie C. 2001. Deletion of MUD2, the yeast homolog of U2AF65, can bypass the requirement for Sub2, an essential spliceosomal ATPase. Genes Dev 15: 42-49.

Libri D, Graziani N, Saguez C, Boulay J. 2001. Multiple roles for the yeast SUB2/yUAP56 gene in splicing. Genes Dev 15: 36-41.

Liu Z, Luyten I, Bottomley MJ, Messias AC, Houngninou-Molango S, Sprangers R, Zanier K, Krämer A, Sattler M. 2001. Structural basis for recognition of the intron branch site RNA by splicing factor 1 . Science 294: 1098-1102.
Munding EM, Igel AH, Shiue L, Dorighi KM, Treviño LR, Ares M Jr. 2010. Integration of a splicing regulatory network within the meiotic gene expression program of Saccharomyces cerevisiae. Genes Dev 24: 2693-2704.

Pleiss JA, Whitworth GB, Bergkessel M, Guthrie C. 2007. Transcript specificity in yeast pre-mRNA splicing revealed by mutations in core spliceosomal components. PLoS Biol 5: e90.

Qiu ZR, Schwer B, Shuman S. 2011a. Determinants of Nam8-dependent splicing of meiotic pre-mRNAs. Nucleic Acids Res 39: 3427-3445.

Qiu ZR, Shuman S, Schwer B. 2011b. An essential role for trimethylguanosine RNA caps in Saccharomyces cerevisiae meiosis and their requirement for splicing of $S A E 3$ and $P C H 2$ meiotic pre-mRNAs. Nucleic Acids Res 39: 5633-5646.

Qiu ZR, Schwer B, Shuman S. 2011c. Defining the Mer1 and Nam8 meiotic splicing regulons by cDNA rescue. RNA 17: 1648-1654.

Qiu ZR, Chico L, Chang J, Shuman S, Schwer B. 2012. Genetic interactions of hypomorphic mutations in the $\mathrm{m}^{7} \mathrm{G}$ cap-binding pocket of yeast nuclear cap binding complex: an essential role for Cbc2 in meiosis via splicing of MER3 pre-mRNA. RNA 18: 1996-2011.

Rain JC, Rafi Z, Legrain P, Krämer A. 1998. Conservation of functional domains involved in RNA binding and protein-protein interactions in human and Saccharomyces cerevisiae pre-mRNA splicing factor SF1. RNA 4: 551-565.

Rutz B, Séraphin B. 1999. Transient interaction of BBP/ScSF1 and Mud2 with the splicing machinery affects the kinetics of spliceosome assembly. RNA 5: 819-831.

Rutz B, Séraphin B. 2000. A dual role for BBP/ScSF1 in nuclear premRNA retention and splicing. EMBO J 19: 1873-1886.

Rymond BC. 2010. The branchpoint binding protein: in and out of the spliceosome cycle. Adv Exp Med Biol 693: 123-141.

Schwer B, Erdjument-Bromage H, Shuman S. 2011. Composition of yeast snRNPs and snoRNPs in the absence of trimethylguanosine caps reveals nuclear cap binding protein as a gained U1 component implicated in the cold-sensitivity of tgs $1 \Delta$ cells. Nucleic Acids Res 39: 6715-6728.

Schwer B, Chang J, Shuman S. 2013. Structure-function analysis of the $5^{\prime}$ end of yeast U1 snRNA highlights genetic interactions with the Msl5 Mud2 branchpoint-binding complex and other spliceosome assembly factors. Nucleic Acids Res 41: 7485-7500.

Shen J, Zhang L, Zhao R. 2007. Biochemical characterization of the ATPase and helicase activity of UAP56, an essential pre-mRNA splicing and mRNA export factor. J Biol Chem 282: 22544-22550.

Spingola M, Ares M Jr. 2000. A yeast intronic splicing enhancer and Nam8p are required for Merlp-activated splicing. Mol Cell 6: 329-338.

Teplova M, Hafner M, Teplov D, Essig K, Tuschl T, Patel DJ. 2013. Structure-function studies of STAR family Quaking proteins bound to their in vivo RNA target sites. Genes Dev 27: 928-940.

Wang Q, Zhang L, Lynn B, Rymond BC. 2008. A BBP-Mud2p heterodimer mediates branchpoint recognition and influences splicing substrate abundance in budding yeast. Nucleic Acids Res 36: 2787-2798.

Zhang M, Green MR. 2001. Identification and characterization of yUAP/Sub2p, a yeast homolog of the essential human pre-mRNA splicing factor hUAP56. Genes Dev 15: 30-35.

Zhao R, Shen J, Green MR, MacMorris M, Blumenthal T. 2004. Crystal structure of UAP56, a DExD/H-box protein involved in pre-mRNA splicing and mRNA export. Structure 12: 1373-1381. 

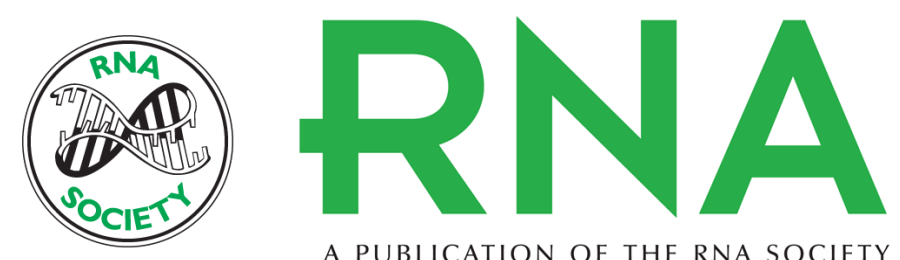

A PUBLICATION OF THE RNA SOCIETY

\section{Structural basis for recognition of intron branchpoint RNA by yeast MsI5 and selective effects of interfacial mutations on splicing of yeast pre-mRNAs}

Agata Jacewicz, Lidia Chico, Paul Smith, et al.

RNA 2015 21: 401-414 originally published online January 13, 2015

Access the most recent version at doi:10.1261/rna.048942.114

Supplemental Material

References

Creative Commons License

Email Alerting Service
http://rnajournal.cshlp.org/content/suppl/2015/01/13/rna.048942.114.DC1

This article cites 35 articles, 18 of which can be accessed free at: http://rnajournal.cshlp.org/content/21/3/401.full.html\#ref-list-1

This article is distributed exclusively by the RNA Society for the first 12 months after the full-issue publication date (see http://rnajournal.cshlp.org/site/misc/terms.xhtml). After 12 months, it is available under a Creative Commons License (Attribution-NonCommercial 4.0 International), as described at http://creativecommons.org/licenses/by-nc/4.0/.

Receive free email alerts when new articles cite this article - sign up in the box at the top right corner of the article or click here.

To subscribe to RNA go to:

http://rnajournal.cshlp.org/subscriptions 